\title{
Investigation of the micro-mechanics of sand-rubber mixtures at very small strains
}

\author{
J. C. Lopera Perez ${ }^{1}$, C. Y. Kwok ${ }^{2}$ and K. Senetakis ${ }^{3}$ \\ ${ }^{1}$ Student, Department of Civil Engineering, The University of Hong Kong, Haking Wong Building, \\ Pokfulam Road, Hong Kong, E-mail: u3002002@hku.hk \\ ${ }^{2}$ Assistant Professor, Department of Civil Engineering, The University of Hong Kong, Haking Wong \\ Building, Pokfulam Road, Hong Kong, E-mail: fiona.kwok@hku.hk (corresponding author) \\ ${ }^{3}$ Assistant Professor, School of Civil and Environmental Engineering, University of New South Wales, \\ Sydney, NSW2052, Australia, E-mail: k.senetakis@unsw.edu.au
}

Received 26 August 2015, revised 30 January 2016, accepted 16 June 2016

\begin{abstract}
This study presents a series of discrete element method (DEM) simulations consisting of mixtures of stiff (sand) and soft (rubber) particles, subjected to monotonic triaxial shearing under constant volume at very small strains where pure elasticity governs the behaviour of the samples. The elastic shear moduli of the simulated pure sand and pure rubber samples were first calibrated to values reported in previous experimental works. Sand-rubber mixtures were then simulated with a focus on small-strain stiffness to examine the role of rubber content on the prevailed micro-mechanisms of the samples. The macro-mechanical response of the numerical mixtures showed a decrease in the elastic shear modulus and the deviatoric stress as the soft particle content increased, in line with observations from laboratory tests. Micro-scale information including coordination number, fabric tensor and normal contact force anisotropy was obtained for all tests and the contribution of each type of contact, i.e. sand-sand, rubber-sand or rubber-rubber, in the overall response of the samples, was analysed. The contact force network in the mixtures changed from being sand-dominated to rubber-dominated, with the presence of an intermediate zone in between rubber and sand particles forming a stable contact force network mainly by sand-rubber contacts. Each type of contact was seen to contribute differently to the deviatoric stress in the system as the rubber content increased.
\end{abstract}

KEYWORDS: Geosynthetics, Discrete-element modelling, Fabric/structure of soils, Micro-mechanics, Particle-scale behaviour, Sand-rubber mixtures, Shear modulus, Stiffness

REFERENCE: Lopera Perez, J. C., Kwok, C. Y. and Senetakis, K. (2016). Investigation of the micro-mechanics of sand-rubber mixtures at very small strains. Geosynthetics International. [http://dx. doi.org/10.1680/jgein.16.00013]

\section{INTRODUCTION}

The use of tire shreds and granulated rubber as new geo-materials or in the form of mixtures with soil has become a popular approach in ground improvement due to its light weight, high damping and high permeability. Examples include: (i) reduction of lateral earth pressures on retaining walls (Humphrey and Sandford 1993; Bernal et al. 1997; Humphrey et al. 1997; Lee et al. 1999; Kaneda et al. 2007) (ii) reduction of vertical stresses and thus settlements (Bosscher et al. 1997; Edil 2004; Zornberg et al. 2004; Edincliler 2007; Tanchaisawat et al. 2010); (iii) improved performance of buried pipes (Uchumura et al. 2007; Tavaloki Mehrjardi et al. 2012; Li et al. 2016); (iv) provision of damping to foundations during liquefaction (e.g. Hazarika et al. 2008; Tsang 2008; Senetakis et al. 2009; Christ et al. 2010; Mavronicola et al. 2010; Pitilakis et al. 2010, 2011; Moghaddas Tafreshi et al.
2014); (v) provision of filter layers for drainage in landfills (Narejo and Shettima 1995; Reddy and Saichek 1998; Edeskar 2006).

One of the most important properties of soil is the elastic shear modulus measured at very small (less than $0.001 \%$ ) and small strains (less than $0.1 \%$ ), which is usually required in advanced modelling for accurate prediction of ground movement (Simpson et al. 1979). Experimental works on sand-rubber mixtures have been carried out covering from very small strains up to large strains (Zornberg et al. 2004; Lee et al. 2007; Özkul and Baykal 2007; Kim and Santamarina 2008; Edincliler and Ayhan 2010; Anastasiadis et al. 2012, Senetakis et al. 2012a, Edincliler and Cagatay 2013; Mashiri et al. 2015; Senetakis and Anastasiadis 2015). However, most of the numerical investigations of sand-rubber mixtures have been focused primarily in the range of medium to large strains (Valdes and Evans 2008; Evans and Valdes 2011; 
Lee et al. 2014). An important effect of the inclusion of rubber particles in sand is the reduction in the maximum shear modulus (Lee et al. 2007; Anastasiadis et al. 2012; Senetakis and Anastasiadis 2015) that is obtained when the behaviour is purely elastic. Attempts have been made to explain the effect from a mechanical point of view. However, explanations are in the form of hypotheses due to the lack of micro-mechanical evidence from laboratory tests, which can usually only provide information at the macro scale.

The aim of this study is to simulate mixtures comprising rubber and sand particles in triaxial loading conditions by employing the discrete element method (DEM) (Cundall and Strack 1979). DEM simulations allowed the tracking of contacts and forces at all loading stages, which is not feasible in laboratory experiments. Another advantage of the numerical simulations carried out in the study is that through relatively simple analysis by means of monotonicstatic shearing, the elastic modulus could be obtained, whereas in laboratory testing only dynamic testing such as the resonant column method can effectively capture pure elastic response. This study focuses on finding a link between the micro-mechanical response and the shear modulus obtained at very small strains with the change in rubber content.

A series of numerical simulations of sand-rubber mixtures with different percentages of rubber content were subjected to triaxial monotonic loading in constant volume conditions, in which sand particles were modelled as rigid particles with a high stiffness, whereas rubber particles were modelled as soft particles with a low stiffness. Initially, the simulated pure sand and pure rubber samples were calibrated to obtain similar values of maximum shear modulus and degradation of shear modulus against shear strain to those reported in laboratory experiments by Anastasiadis et al. (2012) that used the resonant column method. Simulations of sand-rubber mixtures were restricted to the same size ratio (i.e. the ratio of the mean size of the sand and rubber was equal to one) while the content of rubber by weight was systematically increased. Even though it is more common to have a larger size of rubber than soil grains in practice, the same size of sand and rubber has been used in laboratory tests. This study follows the previous laboratory work (Anastasiadis et al. 2012; Senetakis et al. 2012b) in order to make comparisons. On the other hand, there are potential applications where the size of the aggregate is large enough to be of the same order as the size of the rubber (typically in the form of tire chips or shreds), such as in railway projects.

\section{NUMERICAL SIMULATIONS}

The DEM code employed in this study corresponds to a modified version of the open-source code LAMMPS (Plimpton 1995). All tests consisted of three-dimensional samples containing 10184 initially non-contacting spherical particles replicating a representative volume element. Boundary effects were avoided by enclosing all particles inside a cuboidal periodic cell (Thornton 2000; Huang et al. 2014). The particle size distribution (PSD) of the numerical sand and rubber used in all simulations is shown in Figure 1. This PSD was almost identical to the corresponding curve of a uniform fine-grained sand of fluvial origin tested by Anastasiadis et al. (2012) and Senetakis et al. (2012b). Both sand and rubber particles had a mean size $\left(D_{50}\right)$ of about $0.22 \mathrm{~mm}$ and a coefficient of uniformity $\left(C_{\mathrm{u}}\right)$ of 1.4. Note that for this grain size distribution, the sand is classified as SP (poorly graded sand) following the USCS classification system (ASTM D2487-00) and the rubber is classified as granulated rubber or particulate rubber following the ASTM specification (ASTM D6270-98). Views of the numerical samples for the clean sand and all mixtures at the end of an isotropic compression of $100 \mathrm{kPa}$ are included in Figure 2. It should be noted that sand and rubber particles are modelled as perfect spheres and thus shape effects that can greatly influence the macro-mechanical response (Wei and Yang 2014) cannot be simulated. The stresses within the periodic cell were determined from the stress tensor as defined in Equation 1

$$
\overline{\boldsymbol{\sigma}}_{i j}=\frac{1}{V} \sum_{1}^{N_{\mathrm{c}}} \boldsymbol{H}_{\dot{i}}^{\mathbf{c}}
$$

where $\overline{\boldsymbol{\sigma}}_{i j}$ is the stress tensor, $V$ is the volume of the periodic cell, $N_{\mathrm{c}}$ is the total number of contacts, $\boldsymbol{I}_{\dot{t}}^{\mathrm{e}}$ and $\boldsymbol{f}_{\dot{\mathrm{k}}}^{\mathrm{\epsilon}}$ are the branch vector and inter-particle contact force corresponding to contact $c$ respectively (Bagi 1996; Potyondy and Cundall 2004). A simplified Hertz-Mindlin contact model was used with the normal and tangential

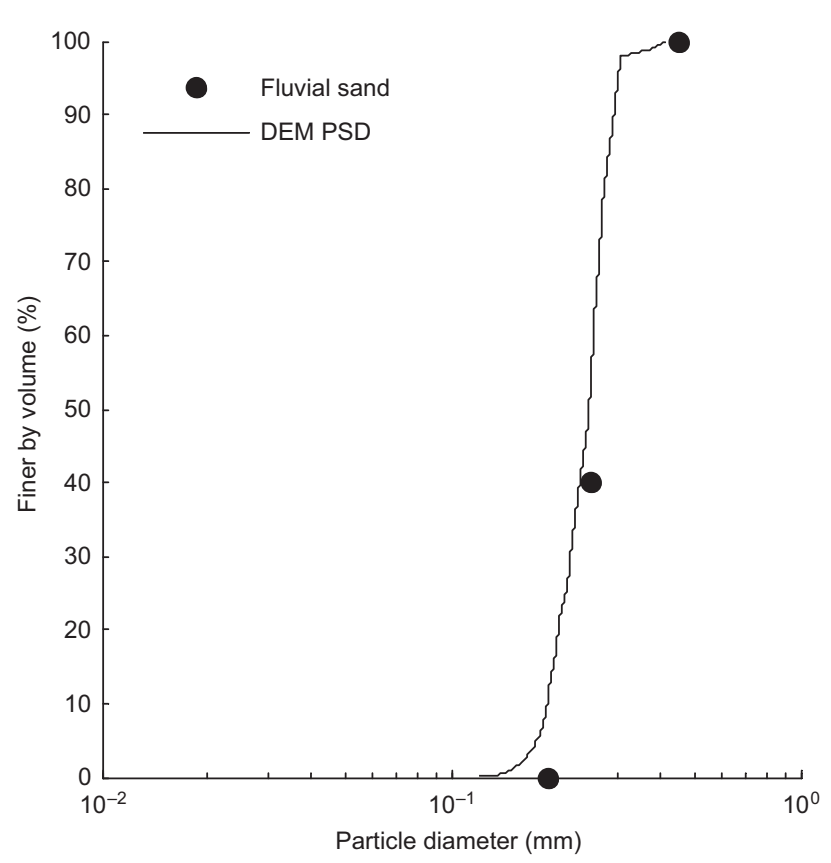

Figure 1. Particle size distribution of numerical samples compared with laboratory data for a uniform sand. Data for the uniform sand matched with a natural sand tested by Anastasiadis et al. (2012) and Senetakis et al. (2012a, 2012b) 


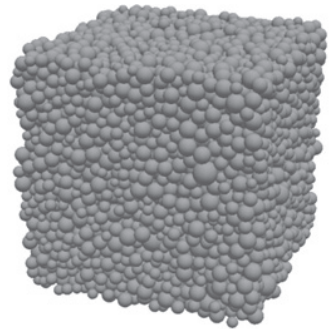

(a)

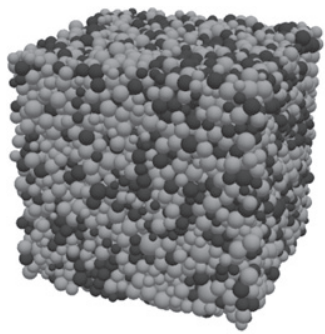

(d)

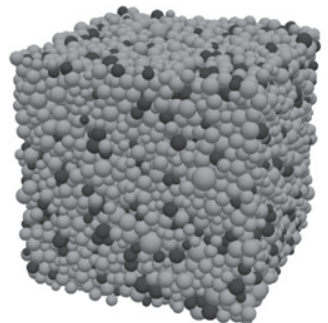

(b)

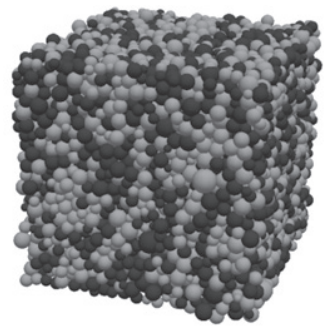

(e)

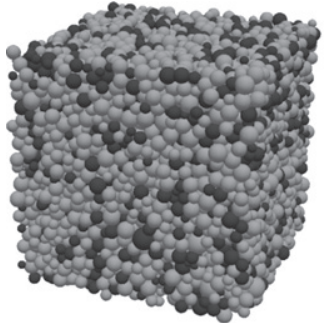

(c)

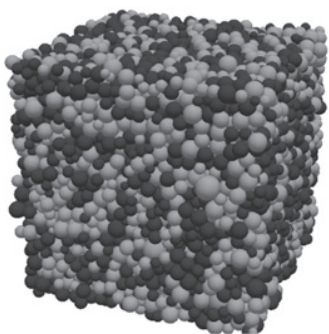

(f)

Figure 2. Numerical samples at the end of the isotropic compression stage of (a) clean sand (10184 sand particles - 0 rubber) and mixtures with (b) $10 \%$ (8212 sand particles - 1972 rubber) (c) $20 \%$ (6916 sand particles - 3268 rubber) (d) $30 \%$ (5945 sand particles - 4239 rubber) (e) $40 \%$ (5201 sand particles - 4983 rubber) and (f) $50 \%$ of rubber content by weight (4689 sand particles - 5495 rubber)

stiffnesses calculated as shown in Equations 2 and 3, respectively

$$
\begin{aligned}
& k_{\mathrm{n}}=\frac{2 G}{1-v} \tilde{R}^{1 / 2} \delta_{\mathrm{n}}^{1 / 2} \\
& k_{\mathrm{t}}=\frac{4 G}{2-v} \tilde{R}^{1 / 2} \delta_{\mathrm{n}}^{1 / 2}
\end{aligned}
$$

where $\tilde{R}$ is the equivalent radius between two particles in contact $i$ and $j$, obtained as: $\tilde{R}=R_{i} R_{j} / R_{i}+R_{j}$, and $\delta_{\mathrm{n}}$ is the contact overlap. The Hertz-Mindlin contact model used in our simulations uses an approximation of the theory of Mindlin and Deresiewicz (1953) as discussed by O'Sullivan (2011), in which only the initial shear modulus is used. This contact model has been widely adopted in DEM simulations, which have successfully captured typical soil behaviour characteristics (Sitharam et al. 2009; Yimsiri and Soga 2010; Barreto and O'Sullivan 2012). Following the properties of quartz and unconsolidated sands (Simmons and Brace 1965; Bachrach et al. 2000), a particle Poisson's ratio ( $v$ ) of 0.12 was assigned for the sand to simulate the weakening of the particle contacts once the roughness of the particle contact is considered (Manificat and Guéguen 1998). For the rubber particle, a $v$ of 0.45 was adopted in line with their small volume compressibility as observed by Beatty (1991). Sand particles had a solid density $(\rho)$ of $2650 \mathrm{~kg} / \mathrm{m}^{3}$, while rubber particles had a $\rho$ of $1100 \mathrm{~kg} / \mathrm{m}^{3}$. A small local damping coefficient of 0.1 was used for all simulations while gravity was inactive during these simulations. The particle shear modulus for both materials $\left(G^{\mathrm{p}}\right)$ was systematically varied in order to match the maximum elastic shear modulus $\left(G_{\max }\right)$ found from laboratory tests. For the mixtures, $G$ and $v$ in Equations 2 and 3 were calculated as the average value of the two particles in contact. All simulations were run on a high-performance cluster using a stable time step $\left(t_{\text {crit }}\right)$ calculated as $(\mathrm{m} / \mathrm{max}$ $\left.\left[k_{\mathrm{n}}, k_{\mathrm{t}}\right]\right)^{1 / 2}$ with $m$ being the mass of the smallest particle and assuming a $5 \%$ overlap between the two smallest particles for all contacts. Values for $t_{\text {crit }}$ ranged from $2.4 \times 10^{-7} \mathrm{~s}$ to $5.3 \times 10^{-9} \mathrm{~s}$, the largest corresponding to rubber samples because of the low $G^{\mathrm{p}}$ resulting in lower matrix stiffness, while the smallest value corresponded to either sand samples or mixtures controlled by sand particles, with the higher $G^{\mathrm{p}}$ yielding higher stiffness. The $t_{\text {crit }}$ obtained from this approach agrees with the suggestions by O'Sullivan and Bray (2004).

An isotropic state was reached by deforming the periodic cell until a mean effective stress $\left(p_{0}^{\prime}\right)$ of 50,100 and $200 \mathrm{kPa}$ for the sand and mixture samples and a $p_{0}^{\prime}$ of 50,75 and $100 \mathrm{kPa}$ for rubber samples was reached. The void ratio of each sample at the end of isotropic compression was controlled using different inter-particle friction coefficients $(\mu)$ of $0.01,0.05,0.1,0.25$ and 1.0 during the isotropic compression stage. The system was subjected to numerical cycling to ensure that both $p^{\prime}$ and the number of contacts became constant, indicating equilibrium. After the completion of the isotropic compression stage, sand particles were assigned an interparticle friction coefficient $(\mu)$ of 0.25 (Senetakis et al. 2013a, 2013b; Huang et al. 2014), while rubber particles were set a $\mu$ of 1.0 (Valdes and Evans 2008; Evans and Valdes 2011; Lee et al. 2014). Lower void ratios are expected, as the particle shear modulus decreases as overlap ratios start incrementing. However, the effect of the particle shear modulus on the initial packing diminishes as the shear modulus increases. Numerical simulations of constant volume $(\mathrm{CV})$ tests were performed with the strain rate controlled, covering from the very small to relatively medium strains. Compression drained shear (CDS) tests were also performed and the data are similar to those of $\mathrm{CV}$ tests. The incremental axial 
deformation of the periodic cell was set to $d \varepsilon=1 \times 10^{-8}$. The strain rate $(\dot{\varepsilon})$ used for all tests was obtained by dividing $d \varepsilon$ by the $t_{\text {crit }}$. The inertial number defined as $I=\dot{\varepsilon} d\left(\rho / p^{\prime}\right)^{1 / 2}$ where $\dot{\varepsilon}$ is the shear rate, $d$ is the mean size of grains in the assembly, $\rho$ is the grain density, and $p^{\prime}$ is the mean effective stress, was used to ensure quasi-steady conditions during the shearing process, where a limit of $I \leq 1 \times 10^{-3}$ would be sufficient to maintain quasi-steady conditions (MiDi 2004; daCruz et al. 2005). Table 1 summarises the simulations carried out in this study. In this table the test notation is divided into four parts for the tests used for calibration, indicating the type of material (CS for clean sand, $R$ for pure rubber and $M(X)$ for mixture, where $X$ indicates the percentage of rubber), particle shear modulus, void ratio after isotropic compression and mean effective stress reached at the initial state. Mixture tests notation includes three parts consisting of the type of mixture, the void ratio after the completion of the isotropic compression stage and the mean effective stress reached at the initial state.

\section{CALIBRATION OF $\boldsymbol{G}_{\mathrm{MAX}}$}

As indicated in Equations 2 and 3, contact stiffness $(k)$ depends greatly on the particle shear modulus $\left(G^{\mathrm{p}}\right)$. In the search for micro-mechanical insights into the effect of rubber content on the elastic shear modulus $\left(G_{\max }\right), G^{\mathrm{p}}$ was calibrated, which yielded a $k$ that allowed an amount of stress at a particular deformation within a dense sample that would match the real $G_{\max }$. Initially, the $G_{\max }$ of a clean uniform river sand studied by Anastasiadis et al. (2012) and Senetakis et al. (2012b) was matched as shown in Figure 3a, where $G_{\max }$ is plotted against $p^{\prime}$. Different values of particle shear modulus ranging from 4 to $29 \mathrm{GPa}$ were used. For each set of particle shear moduli, different initial coefficients of friction $\left(\mu_{\text {iso }}\right)$ were used to create samples with different densities to investigate its effect on $G_{\max }$ (Table 1). $G_{\max }$ was calculated as $G_{\max }=(2 / 3) q / \varepsilon_{\mathrm{q}}$, where $q$ is the deviatoric stress and $\varepsilon_{\mathrm{q}}$ is the shear strain calculated as the difference between the major and minor principal strains $\left(\varepsilon_{1}-\varepsilon_{3}\right) . G_{\max }$ was obtained within $1 \times 10^{-4}$ to $5 \times 10^{-4}$ of shear strain $\left(\varepsilon_{\mathrm{d}}\right)$.

Samples with $G^{\mathrm{p}}=4 \mathrm{GPa}$ showed systematically lower $G_{\max }$ compared to the values obtained in the laboratory tests, with $G_{\max }$ decreasing as void ratio increased. For numerical samples where a $G^{\mathrm{p}}=29 \mathrm{GPa}$ was assigned, $G_{\max }$ appeared higher than those from the laboratory tests and the influence of the void ratio was less pronounced. A marked decrease in $G_{\max }$ was obtained only for the numerical sample with $e_{0}=0.672$. Closer agreement between values of $G_{\max }$ in laboratory test results and numerical simulations were found by assigning a $G^{\mathrm{p}}=7 \mathrm{GPa}$ where the densest numerical sample, with a void ratio $e_{0}=0.557$, almost matched the laboratory data. Note that the black diamonds in Figure 3 a correspond to a numerical sample of $G^{\mathrm{p}}=8 \mathrm{GPa}$ with an initial void ratio of 0.556 , which show the optimum match of $G_{\max }$ between laboratory data and numerical simulations.
A similar procedure was carried out to match the $G_{\max }$ from the simulated samples to the real $G_{\max }$ for pure rubber based on the resonant column test results in torsional mode vibration obtained by Anastasiadis et al. (2012) for pure rubber. Figure $3 \mathrm{~b}$ includes $G_{\max }$ against $p^{\prime}$ for six sets of simulations with $G^{\mathrm{p}}$ ranging from $G^{\mathrm{p}}=2.5 \mathrm{MPa}$ to $G^{\mathrm{p}}=12 \mathrm{MPa}$, where the numerical samples set with $G^{\mathrm{p}}=12 \mathrm{MPa}$ agreed best with the $G_{\max }$ obtained from the laboratory tests. From the calibration, the ratio of the $G^{\mathrm{p}}$ of sand and the $G^{\mathrm{p}}$ of rubber adopted in this study is 667 , which is different from the ratio of $10^{3}$ employed by Lee et al. (2014) and the ratio of $10^{4}$ used by Evans and Valdes (2011).

The effect of different $G^{\mathrm{p}}$ and $e_{0}$ during isotropic compression on the degradation of the $G$ of the numerical samples was also investigated. Figure $4 \mathrm{a}$ shows the normalised shear modulus $\left(G / G_{\max }\right)$ against $\varepsilon_{\mathrm{d}}$, where the parts of the figure correspond to the dense, medium dense and loose states of the numerical samples. It is shown that when $G^{\mathrm{p}}$ increased, the degradation of $G$ was faster at all densities. The cross markers in Figure 4 correspond to laboratory results from a clean sand that the numerical sand was calibrated to. The numerical sample that matched the $G_{\max }$ from laboratory tests showed good agreement in the degradation of $G$ as seen in the top part of the figure in Figure 4a. In Figure 4b, the parts of the figure correspond to a $G^{\mathrm{p}}$ of $4 \mathrm{GPa}, 7 \mathrm{GPa}$ and $29 \mathrm{GPa}$, with different void ratios. In general, looser samples tend to have a faster degradation of $G$ regardless of the value of $G^{\mathrm{p}}$. Results presented in the following section correspond to samples with test IDs of CS-8e9-0.556 for clean sand and R-12e6-0.563 for simulated rubber; M10 to M50 indicate a mix by weight of clean sand and clean rubber with percentages of rubber increasing from 10 to $50 \%$ by mixture weight in increments of $10 \%$.

\section{RESULTS}

\subsection{Macro-scale response or sand-rubber mixtures}

Figure 5a plots $G_{\max }$ against $p^{\prime}$ for both numerical and laboratory data corresponding to clean sand, rubber and mixtures. The numerical samples showed that as the rubber content increased $G_{\max }$ decreased, with values of $G_{\text {max }}$ in good agreement with those obtained from laboratory data. $G_{\max }$ is plotted against rubber content in Figure $5 \mathrm{~b}$. For a given $p_{0}^{\prime}$, an exponential decay of $G_{\max }$ was observed with an increase of rubber content, and stronger decays were observed for a greater $p_{0}^{\prime}$. The effect of void ratio on the overall response of the sand was witnessed in Figures 3 and 4b; generally, as the void ratio increases, lower values of $G_{\max }$ were found together with a faster degradation of $G_{\max }$ with strain. Similarly for the mixtures, as the rubber content increases the sand-rubber mixtures become looser, which gives lower values of $G_{\max }$. Besides, as the rubber content increased the difference in $G_{\max }$ between various $p_{0}^{\prime}$ became less pronounced. F, for example, M50 samples sheared at $p_{0}^{\prime}=50 \mathrm{kPa}$ and $100 \mathrm{kPa}$ almost converged to the same values of $G_{\max }$. The degradation of $G$ is illustrated in Figure $5 \mathrm{c}$, where the 
Table 1. List of simulations conducted

\begin{tabular}{|c|c|c|c|c|c|c|c|}
\hline Set test ID & $e_{0}$ & $p_{0}^{\prime}(\mathrm{kPa})$ & (क) & $\mu_{\text {iso }}$ & Rubber content (\%) & Sand particles & Rubber particles \\
\hline CS-4e9-0.5549-50 & 0.5549 & 50 & $4.00 \times 10^{9}$ & 0.01 & & & \\
\hline CS-4e9-0.5525-100 & 0.5525 & 100 & $4.00 \times 10^{9}$ & 0.01 & & & \\
\hline CS-4e9-0.5489-200 & 0.5489 & 200 & $4.00 \times 10^{9}$ & 0.01 & & & \\
\hline CS-4e9-0.5855-50 & 0.5855 & 50 & $4.00 \times 10^{9}$ & 0.05 & & & \\
\hline CS-4e9-0.5831-100 & 0.5831 & 100 & $4.00 \times 10^{9}$ & 0.05 & & & \\
\hline CS-4e9-0.5797-200 & 0.5797 & 200 & $4.00 \times 10^{9}$ & 0.05 & & & \\
\hline CS-4e9-0.6163-50 & 0.6163 & 50 & $4.00 \times 10^{9}$ & 0.10 & & & \\
\hline CS-4e9-0.6163-100 & 0.6139 & 100 & $4.00 \times 10^{9}$ & 0.10 & & & \\
\hline CS-4e9-0.6102-200 & 0.6102 & 200 & $4.00 \times 10^{9}$ & 0.10 & & & \\
\hline CS-4e9-0.6674-50 & 0.6674 & 50 & $4.00 \times 10^{9}$ & 0.25 & & & \\
\hline CS-4e9-0.6648-100 & 0.6648 & 100 & $4.00 \times 10^{9}$ & 0.25 & & & \\
\hline CS-4e9-0.6607-200 & 0.6607 & 200 & $4.00 \times 10^{9}$ & 0.25 & & & \\
\hline CS-7e9-0.5568-50 & 0.5568 & 50 & $7.00 \times 10^{9}$ & 0.01 & & & \\
\hline CS-7e9-0.5516-100 & 0.5516 & 100 & $7.00 \times 10^{9}$ & 0.01 & & & \\
\hline CS-7e9-0.6168-200 & 0.6168 & 200 & $7.00 \times 10^{9}$ & 0.01 & & & \\
\hline CS-7e9-0.5918-50 & 0.5918 & 50 & $7.00 \times 10^{9}$ & 0.05 & & & \\
\hline CS-7e9-0.5902-100 & 0.5902 & 100 & $7.00 \times 10^{9}$ & 0.05 & & & \\
\hline CS-7e9-0.5877-200 & 0.5877 & 200 & $7.00 \times 10^{9}$ & 0.05 & & & \\
\hline CS-7e9-0.6168-50 & 0.6168 & 50 & $7.00 \times 10^{9}$ & 0.10 & & & \\
\hline CS-7e9-0.6152-100 & 0.6152 & 100 & $7.00 \times 10^{9}$ & 0.10 & - & 10184 & 0 \\
\hline CS-7e9-0.6127-200 & 0.6127 & 200 & $7.00 \times 10^{9}$ & 0.10 & & & \\
\hline CS-7e9-0.6705-50 & 0.6705 & 50 & $7.00 \times 10^{9}$ & 0.25 & & & \\
\hline CS-7e9-0.6687-100 & 0.6687 & 100 & $7.00 \times 10^{9}$ & 0.25 & & & \\
\hline CS-7e9-0.6659-200 & 0.6659 & 200 & $7.00 \times 10^{9}$ & 0.25 & & & \\
\hline CS-29e9-0.5578-50 & 0.5578 & 50 & $2.90 * 10^{10}$ & 0.01 & & & \\
\hline CS-29e9-0.5567-100 & 0.5567 & 100 & $2.90 \times 10^{10}$ & 0.01 & & & \\
\hline CS-29e9-0.5548-200 & 0.5548 & 200 & $2.90 \times 10^{10}$ & 0.01 & & & \\
\hline CS-29e9-0.5702-50 & 0.5702 & 50 & $2.90 \times 10^{10}$ & 0.05 & & & \\
\hline CS-29e9-0.5697-100 & 0.5697 & 100 & $2.90 \times 10^{10}$ & 0.05 & & & \\
\hline CS-29e9-0.5688-200 & 0.5688 & 200 & $2.90 \times 10^{10}$ & 0.05 & & & \\
\hline CS-29e9-0.5748-50 & 0.5748 & 50 & $2.90 \times 10^{10}$ & 0.10 & & & \\
\hline CS-29e9-0.5743-100 & 0.5743 & 100 & $2.90 \times 10^{10}$ & 0.10 & & & \\
\hline CS-29e9-0.5735-200 & 0.5735 & 200 & $2.90 \times 10^{10}$ & 0.10 & & & \\
\hline CS-29e9-0.6717-50 & 0.6717 & 50 & $2.90 \times 10^{10}$ & 0.25 & & & \\
\hline CS-29e9-0.6709-100 & 0.6709 & 100 & $2.90 \times 10^{10}$ & 0.25 & & & \\
\hline CS-29e9-0.6698-200 & 0.6698 & 200 & $2.90 \times 10^{10}$ & 0.25 & & & \\
\hline CS-8e9-0.556-50 & 0.5560 & 50 & $8.00 \times 10^{9}$ & 0.01 & & & \\
\hline CS-8e9-0.5545-100 & 0.5545 & 100 & $8.00 \times 10^{9}$ & 0.01 & & & \\
\hline CS-8e9-0.5529-200 & 0.5529 & 200 & $8.00 \times 10^{9}$ & 0.01 & & & \\
\hline R-2.5e6-0.409-50 & 0.4090 & 50 & $2.50 \times 10^{6}$ & & & & \\
\hline R-2.5e6-0.3429-75 & 0.3429 & 75 & $2.50 \times 10^{6}$ & & & & \\
\hline R-2.5e6-0.2896-100 & 0.2896 & 100 & $2.50 \times 10^{6}$ & & & & \\
\hline R-5e6-0.4615-50 & 0.4915 & 50 & $5.00 \times 10^{6}$ & & & & \\
\hline R-5e6-0.4480-75 & 0.4480 & 75 & $5.00 \times 10^{6}$ & & & & \\
\hline R-5e6-0.4043-100 & 0.4043 & 100 & $5.00 \times 10^{6}$ & & & & \\
\hline R-6e6-0.5080-50 & 0.5080 & 50 & $6.00 \times 10^{6}$ & & & & \\
\hline R-6e6-0.4662-75 & 0.4662 & 75 & $6.00 \times 10^{6}$ & & & & \\
\hline R-6e6-0.4294-100 & 0.4294 & 100 & $6.00 \times 10^{6}$ & & & & \\
\hline $\mathrm{R}-8 \mathrm{e} 6-0.5330-50$ & 0.5330 & 50 & $8.00 \times 10^{6}$ & 1.00 & 100 & 0 & 10184 \\
\hline R-8e6-0.4964-75 & 0.4964 & 75 & $8.00 \times 10^{6}$ & & & & \\
\hline R-8e6-0.4663-100 & 0.4663 & 100 & $8.00 \times 10^{6}$ & & & & \\
\hline R-10e6-0.5506-50 & 0.5506 & 50 & $1.00 \times 10_{2}^{7}$ & & & & \\
\hline $\mathrm{R}-10 \mathrm{e} 6-0.5301-75$ & 0.5301 & 75 & $1.00 \times 10^{7}$ & & & & \\
\hline R-10e6-0.4912-100 & 0.4912 & 100 & $1.00 \times 10^{7}$ & & & & \\
\hline R-12e6-0.5625-50 & 0.5625 & 50 & $1.20 \times 10^{7}$ & & & & \\
\hline R-12e6-0.5301-75 & 0.5301 & 75 & $1.20 \times 10^{7}$ & & & & \\
\hline R-12e6-0.5035-100 & 0.5035 & 100 & $1.20 \times 10^{7}$ & & & & \\
\hline M10-0.5689-50 & 0.5689 & 50 & & & & & \\
\hline M10-0.5637-100 & 0.5637 & 100 & & & 10 & 8212 & 1972 \\
\hline M10-0.5578-200 & 0.5578 & 200 & & & & & \\
\hline M20-0.5965-50 & 0.5965 & 50 & & & & & \\
\hline M20-0.5878-100 & 0.5878 & 100 & & & 20 & 6916 & 3268 \\
\hline M20-0.5757-200 & 0.5757 & 20 & & & & & \\
\hline M30-0.6176-50 & 0.6176 & 50 & & & & & \\
\hline M30-0.604-100 & 0.6040 & 100 & Sand: $8.00 \times 10^{9}$ & Sand: 0.01 , & 30 & 5945 & 4239 \\
\hline M30-0.5865-200 & 0.5865 & 200 & Rubber: $12.00 \times 10^{6}$ & Rubber: 1.00 & & & \\
\hline M40-0.6316-50 & 0.6316 & 50 & & & & & \\
\hline M40-0.6158-100 & 0.6158 & 100 & & & 40 & 5201 & 4983 \\
\hline M40-0.5936-200 & 0.5936 & 200 & & & & & \\
\hline M50-0.6390-50 & 0.6390 & 50 & & & & & \\
\hline M50-0.6199-100 & 0.6199 & 100 & & & 50 & 4689 & 5495 \\
\hline M50-0.5952-200 & 0.5952 & 200 & & & & & \\
\hline
\end{tabular}




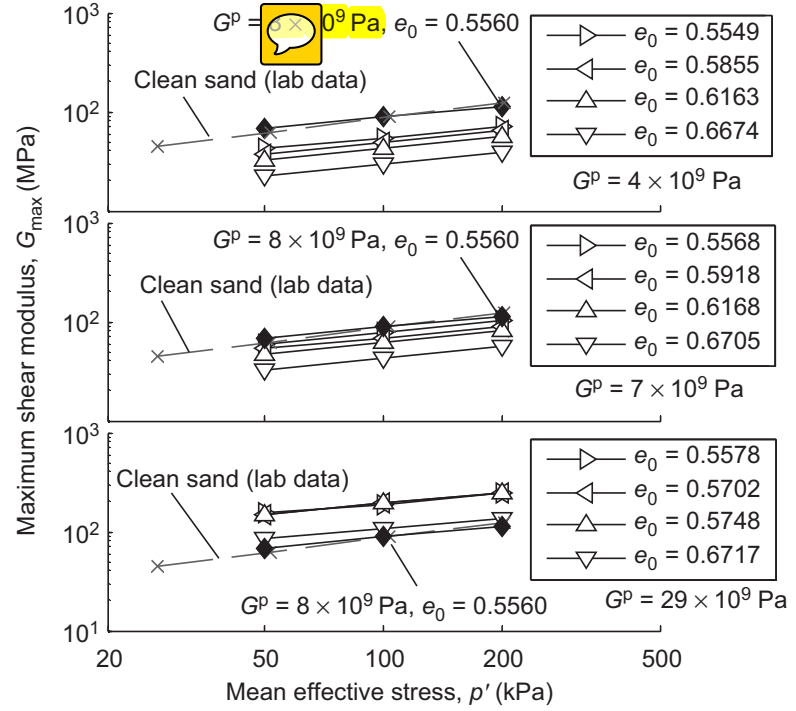

(a)

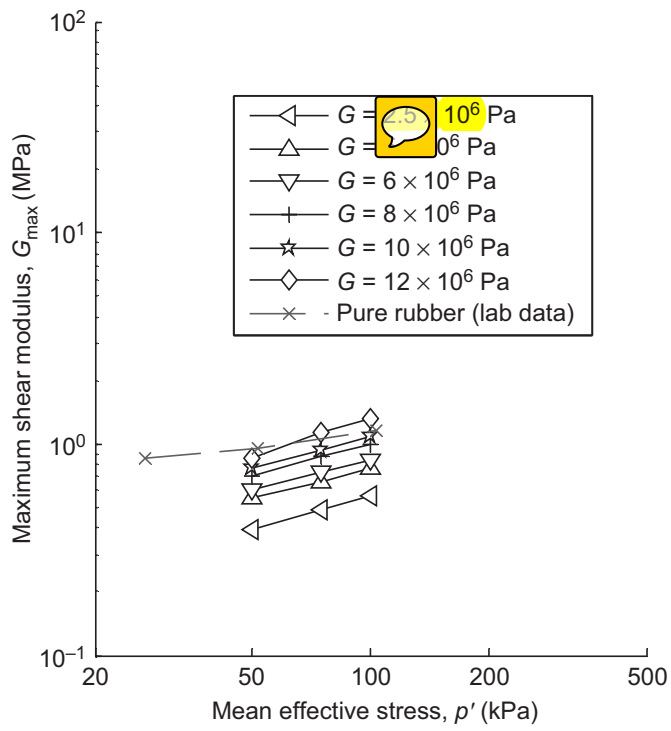

(b)

Figure 3. Maximum shear modulus $\left(G_{\max }\right)$ against mean effective stress $\left(p^{\prime}\right)$ for clean sand (data for clean sand and pure rubber after Anastasiadis et al. 2012). $e_{0}$ for the lab data is equal to 0.588 . Values for $e_{0}$ for the simulated tests correspond to $p_{0}^{\prime}=50 \mathrm{kPa}$ (a) calibration for clean sand and (b) calibration for pure rubber

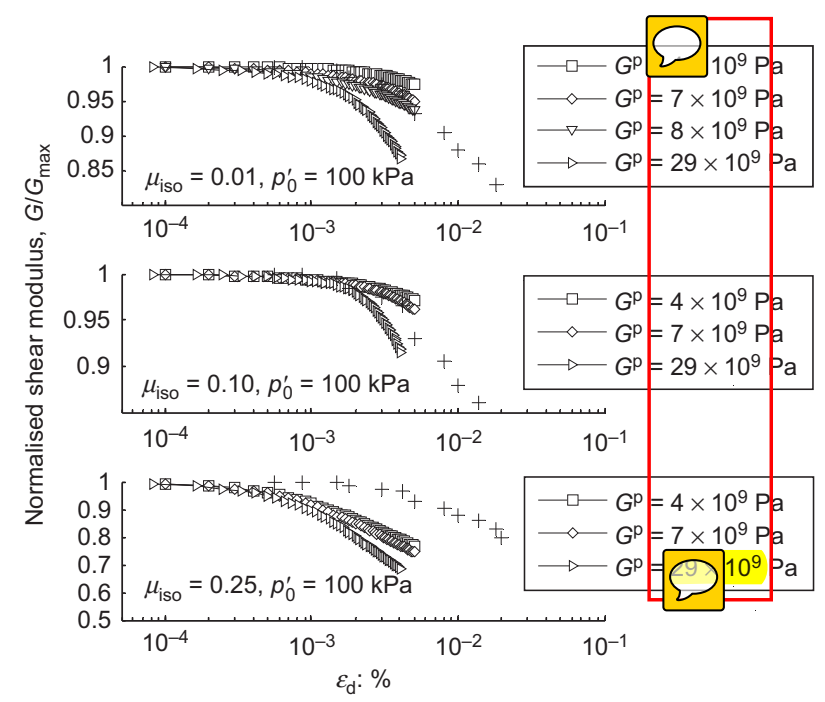

(a)

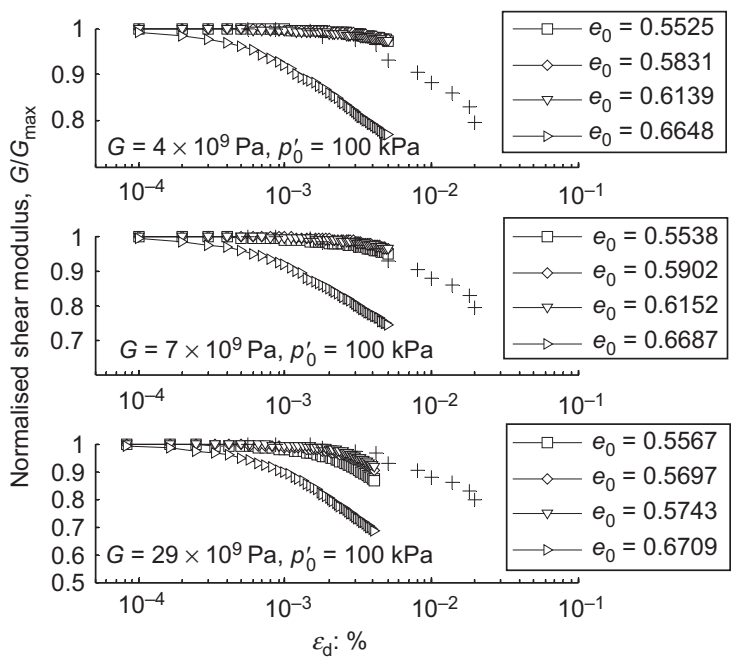

(b)

Figure 4. Normalised shear modulus, $G / G_{\max }$ against shear strain from a $p_{0}^{\prime}$ of $100 \mathrm{kPa}$, (a) effect of particle shear modulus and (b) effect of initial void ratio. (Cross markers correspond to laboratory results of clean sand after Senetakis et al. (2012a))

normalised stiffness $\left(G / G_{\max }\right)$ is plotted against $\varepsilon_{\mathrm{d}}$. The clean sand had the fastest decay, with the rubber particles acting as a damping material delaying the transition from elastic deformations to plastic strains for all mixtures. Laboratory tests by Anastasiadis et al. (2012) and numerical simulations by Lee et al. (2014) reported similar trends for the degradation of stiffness in sand-rubber mixtures, where the decay of stiffness became less significant when the rubber content was larger than $50 \%$.

Figures $6 \mathrm{a}$ and $6 \mathrm{~b}$ showed the sum of the normal stiffness $\left(k_{\mathrm{n}}\right)$ and normal contact force $\left(f_{\mathrm{n}}\right)$ among all contacts in log scale plotted against rubber content for tests sheared from a $p_{0}^{\prime}=100 \mathrm{kPa}$ respectively. Distinction is made by type of contact, with the contribution to the total normal stiffness and normal force of sand-sand, rubber-sand and rubber-rubber contacts included. Due to the increase in rubber particles, fewer sand-sand contacts are available and thus the normal stiffness from sand-sand contacts is seen to decrease. Rubber-sand and rubber-rubber contacts are always seen to contribute less than sand-sand contacts. As a result, the total normal stiffness decreases as more rubber is added to the system. The total normal force acting in the system is seen to remain nearly unchanged as the rubber content varies. As the rubber content increases, the total normal contact force for rubber-sand and rubber-rubber contacts increases, compensating for the marked reduction in total normal force from sand-sand contacts. At a rubber 


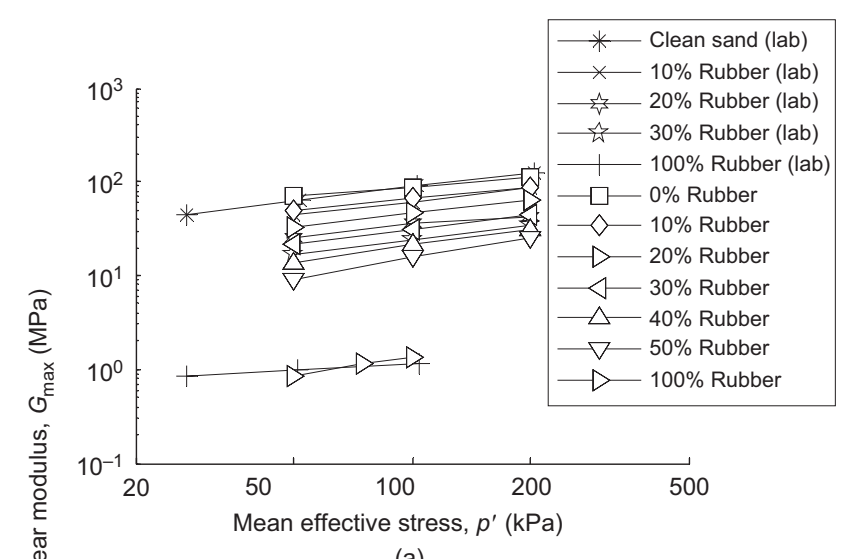

(a)

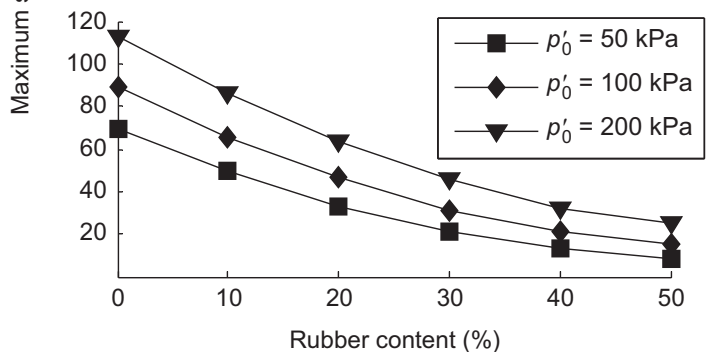

(b)

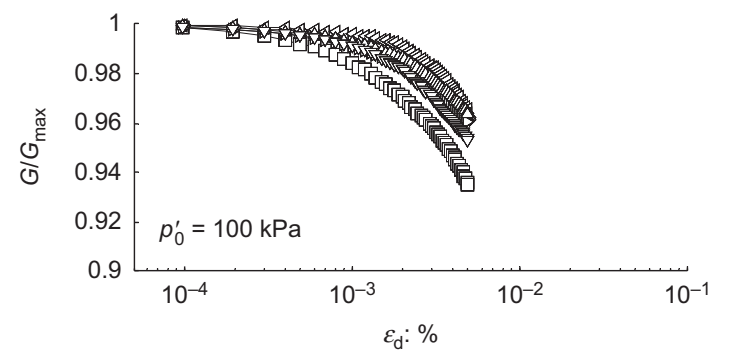

(c)

Figure 5. (a) $G_{\max }$ for different rubber contents against mean effective stress, (b) Normalised shear modulus against shear strain and (c) $G_{\max }$ against rubber content. Lab data after Anastasiadis et al. (2012)

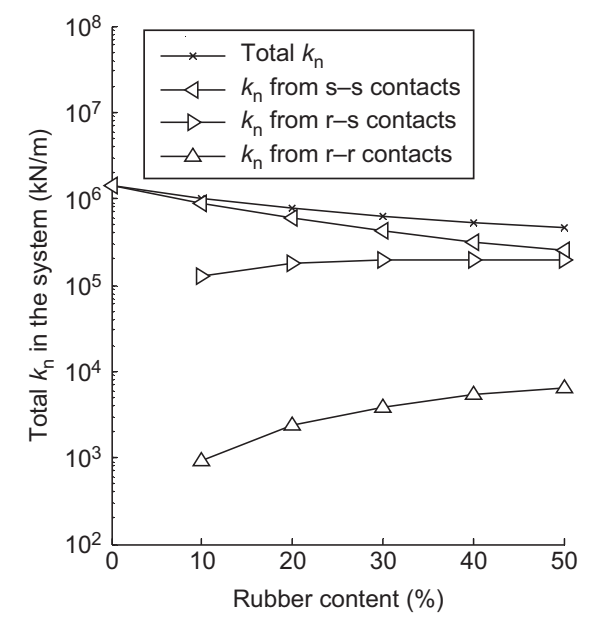

(a) content of $50 \%$, more rubber particles are available in the system and rubber-rubber contacts become the main contributors to the total normal force in the system, with sand-sand contacts contributing less.

\subsection{Micro-mechanical response of sand-rubber mixtures}

In an attempt to better understand the physical basis of the effect of rubber content on the $G_{\max }$ of mixtures, particle-scale parameters were further analysed. The mechanical coordination number $\left(Z_{\mathrm{m}}\right)$ is defined as the average number of contacts per particle, excluding 'rattlers' with zero or one contact (Thornton 2000). A second parameter corresponded to the structural anisotropy (fabric), using the fabric tensor defined by Satake (1982) as shown in Equation 4, which was also incorporated into this study.

$$
\Phi=\frac{1}{N_{\mathrm{c}}} \sum_{1}^{N_{\mathrm{c}}} n_{i} n_{j}
$$

where $N_{\mathrm{c}}$ is the total number of contacts and $n_{i}$ is the normal unit contact. The largest, intermediate and smallest eigenvalues of the fabric tensor are denoted as $\Phi_{1}, \Phi_{2}$ and $\Phi_{3}$ respectively. The deviatoric fabric, $\left(\Phi_{1}-\Phi_{3}\right)$, relates the degree of contact anisotropy. taking into account all contacts and eacrirype of contact allowing the overall $\left(\Phi_{1}-\Phi_{3}\right)$ and $\left(\Phi_{1}-\Phi_{3}\right)$ to be calculated for each type of contact sub-network, i.e. sand-sand, sand-rubber and rubber-rubber.

Stresses in a granular material are related to different sources of anisotropy, which include geometrical anisotropy, normal contact force anisotropy and tangential contact force anisotropy, of which the normal contact force anisotropy $\left(a_{\mathrm{n}}\right)$ is dominant as shown analytically by Rothenburg and Bathurst (1989). A look at the response of $a_{\mathrm{n}}$ in the range of strains considered in this study would be useful to better understand the effect of rubber content on $G_{\max }$. The definition of $a_{\mathrm{n}}$ follows Rothenburg and Bathurst (1989) and Guo and Zhao (2013), with the

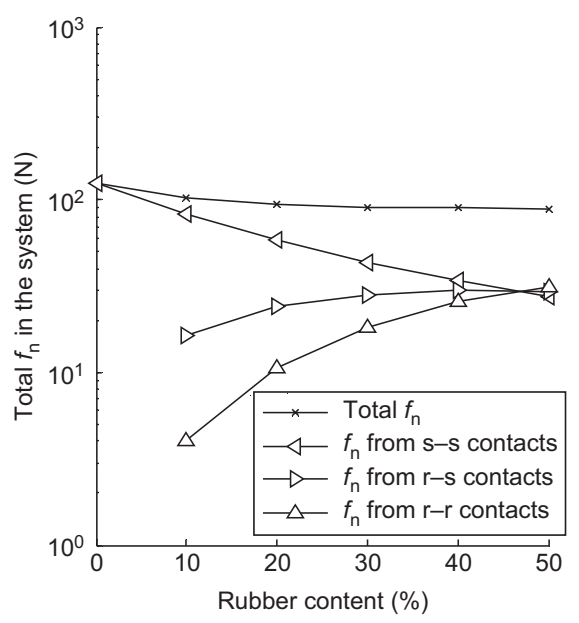

(b)

Figure 6. (a) Total $k_{\mathrm{n}}$ in the system and total $k_{\mathrm{n}}$ by each type of contact, (b) Total $f_{\mathrm{n}}$ in the system and total $f_{\mathrm{n}}$ by each type of contact. $\mathrm{r}-\mathrm{r}$, rubber-rubber; r-s, rubber-sand; s-s, sand-sand 
average normal contact force tensor expressed by Equation 5 (where $\boldsymbol{\Phi}_{i j}^{\prime}$ is the deviatoric part of $\boldsymbol{\Phi}_{i j}$ ). Its probability distribution is given by Equation 6 and $a_{i j}^{\mathrm{n}}=(15 / 2) \boldsymbol{F}_{i j}^{\prime \mathrm{n}} / \bar{f}^{0} \cdot \bar{f}^{0}=\boldsymbol{F}_{i i}^{\mathrm{n}}$ being the average normal contact force calculated considering the entire space $\Omega$, which is different to the mean normal contact force averaged over all contacts. $a_{\mathrm{n}}$ is related to the second invariant of $a_{i j}^{\mathrm{n}}$ as $a_{\mathrm{n}}=\left((3 / 2) a_{i j}^{\mathrm{n}} a_{i j}^{\mathrm{n}}\right)^{1 / 2}$.

$$
\begin{aligned}
\boldsymbol{F}_{\dot{i} \mathrm{n}}^{\mathrm{n}} & =\frac{1}{4 \pi} \int_{\Omega} \bar{f}_{\mathrm{n}}(\Omega) n_{i} n_{j} \mathrm{~d} \Omega \\
& =\frac{1}{N_{\mathrm{c}}} \sum_{1}^{N_{\mathrm{c}}} \frac{f_{\mathrm{n}} n_{i} n_{j}}{1+(15 / 2) \boldsymbol{\Phi}_{i j}^{\prime} n_{\mathrm{k}} n_{1}} \\
\bar{f}_{\mathrm{n}}(\Omega) & =\bar{f}^{0}\left[1+a_{i j}^{\mathrm{n}}\right]
\end{aligned}
$$

Following the same approach, $\boldsymbol{F}_{i j}^{\mathrm{n}}$ was obtained considering all contacts and each type of contact, leading to calculation of the overall $a_{\mathrm{n}}$ and $a_{\mathrm{n}}$ for sand-sand, sandrubber and rubber-rubber sub-networks.

\subsubsection{Coordination number}

An overall $Z_{\mathrm{m}}$ considering all contacts was calculated, and a $Z_{\mathrm{m}}$ for each type of contact (sand-sand, rubber-sand or rubber-rubber) was also obtained as shown in Figure 7a. $Z_{\mathrm{m}}$ for each type of contact was calculated following Minh and Cheng (2013). From Figure 7a it can be seen that with the increase in rubber content, $Z_{\mathrm{m}}$ of sand-sand contacts decreased while the opposite occurred with rubber-rubber contacts. The increase of $Z_{\mathrm{m}}$ for rubbersand contacts was not significant when the rubber content was greater than $20 \%$. For the range of strain considered regardless of the type of contact, $Z_{\mathrm{m}}$ was seen to remain constant.

Figure $7 \mathrm{~b}$ shows $Z_{\mathrm{m}}$ for all samples (sheared from $p_{0}^{\prime}=100 \mathrm{kPa}$ ) against rubber content at $G_{\max }$. The overall responses of $Z_{\mathrm{m}}$ as well as for each type of contact are included. The dotted line at $Z_{\mathrm{m}}=4$ indicates the minimum value required for the stability of a system composed of frictional spheres (Hecke 2010). However, as the rubber content increased, the overall $Z_{\mathrm{m}}$ decreased regardless of $p_{0}^{\prime}$ level. This decrease is due to the high inter-particle friction coefficient for rubber particle contacts, which prevented sliding within the sample among rubber-rubber contacts and thus created looser packing and fewer contacts. Although for all rubber contents the system remained stable, the contribution of each type of contact to overall stability was different. Sand-sand contacts presented an exponential decay of $Z_{\mathrm{m}}$ as rubber content increased, crossing the minimum instability requirement at a rubber content of $20 \%$. Rubber-sand contacts seemed to increase exponentially up to a rubber content of $40 \%$, and beyond that threshold more rubber-sand contacts than sand-sand contacts were available in the system. When $Z_{\mathrm{m}}$ for sandsand contacts was close to becoming unstable, rubber-sand and rubber-rubber contacts tended towards the stable limit, indicating interplay between sand and rubber particles that contributed to the overall stability of the system. At a rubber content of $40 \%$, a crossover occurred where rubber-rubber contacts became the majority in the system and sand-sand contacts were fewer. A rubber content by weight of $40 \%$ seems to be the threshold for the system to become a rubber-like material, while a transition zone from a sand-like material to a rubber-like material was found for a rubber content greater than $20 \%$ (the crossover of sand-sand contacts with the minimum instability requirement) and less than 40\%. Sand-sand contacts dominated the contact force network when the rubber content was less than $20 \%$. The exponential decay seen in $Z_{\mathrm{m}}$ for sand-sand contacts (fewer high-stiffness contacts) is similar to the trend seen for $G_{\max }$ in Figure $5 \mathrm{~b}$. In general, the appearance of fewer high-stiffness contacts and more low-stiffness contacts directly affects $G_{\max }$.

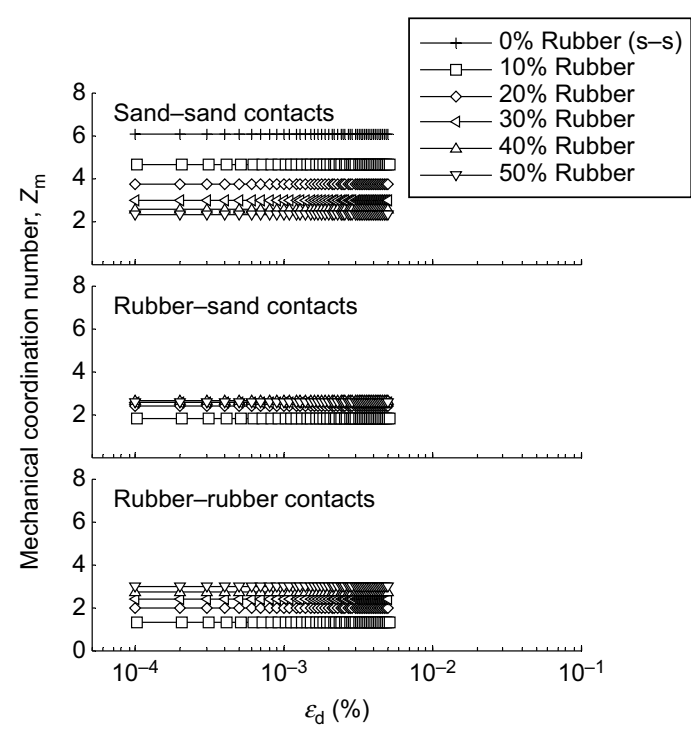

(a)

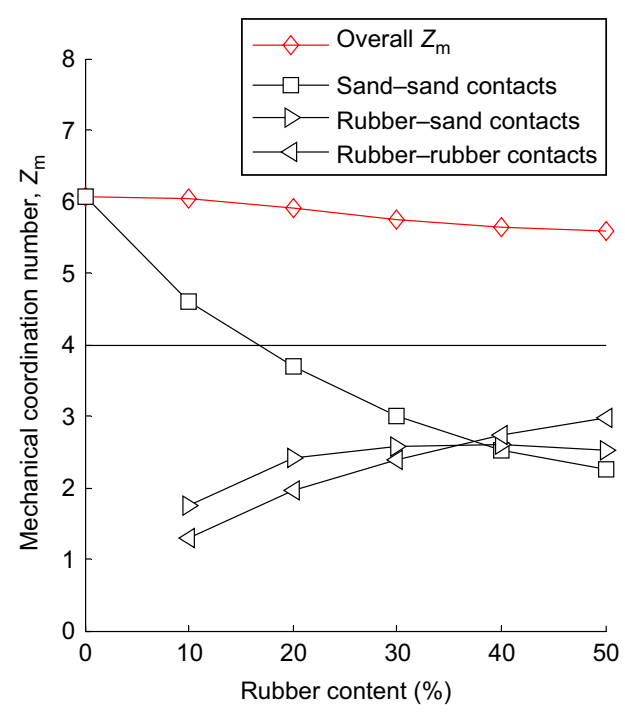

(b)

Figure 7. (a) Mechanical coordination number response during small strains for each type of contact and (b) overall mechanical coordination number, and by each type of contact against rubber content. s-s, sand-sand 


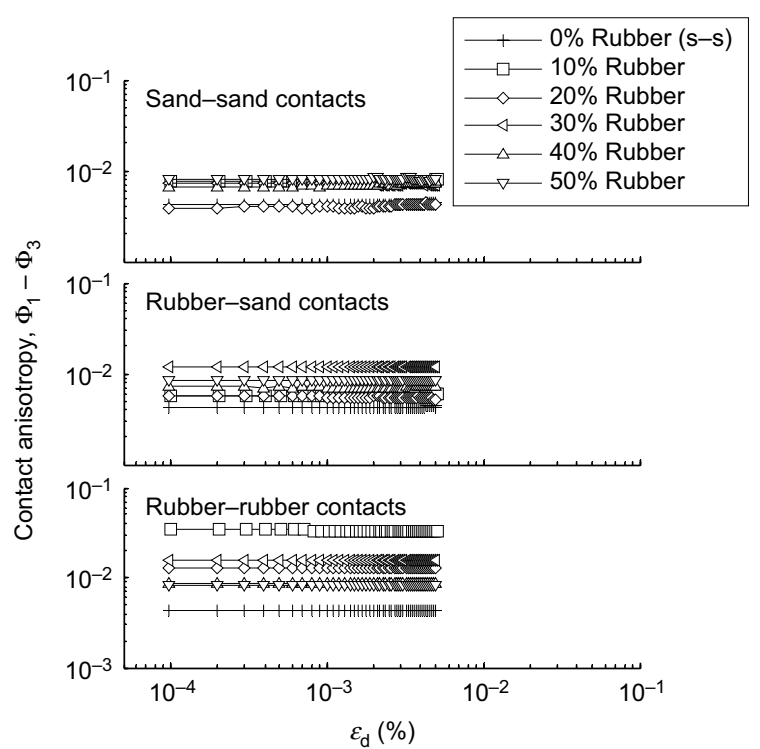

(a)

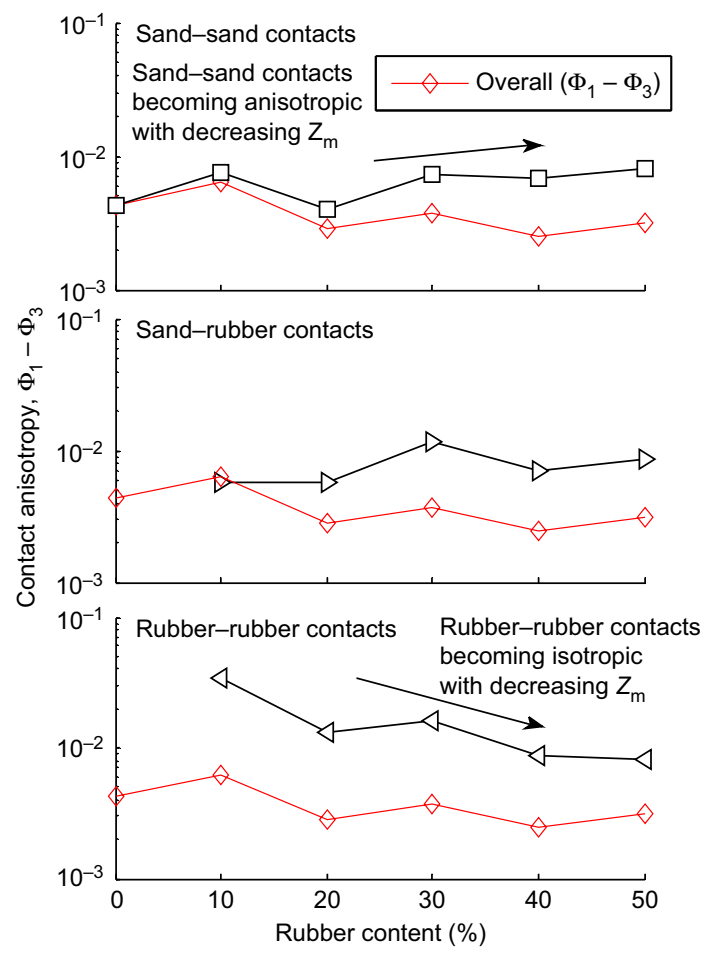

(b)

Figure 8. (a) Contact anisotropy response during small strains for each type of contact and (b) overall contact anisotropy, and by each type of contact against rubber content. $s-s$, sand-sand

\subsubsection{Structural anisotropy}

Figure $8 \mathrm{a}$ shows that with the increase in rubber content there is a general decrease in $\left(\Phi_{1}-\Phi_{3}\right)$ for rubber-rubber contacts, indicating that rubbers are in a more isotropic arrangement. For the rubber-sand contacts, there is first an increase in contact anisotropy then a decrease. The standard method for obtaining $G_{\max }$ from different laboratory tests (for example the resonant column test, bender elements, cyclic testing or monotonic testing) is that $G_{\max }$ must be calculated before an elastic threshold strain is reached. Below that threshold, $G$ remains constant and corresponds to $G_{\max }$ (Oztoprak and Bolton 2013). $Z_{\mathrm{m}}$ and $\left(\Phi_{1}-\Phi_{3}\right)$ in Figures $7 \mathrm{a}$ and $8 \mathrm{~b}$ respectively were inspected throughout the monotonic tests to ensure that the number of contacts and the contact structure remained constant, which indicated that no re-arrangement of particles or complete detachment of contacts was taking place that would lead to plastic deformations within the sample (O'Donovan et al. 2013).

For all tests, $G_{\max }$ was obtained at strains in the order of $10^{-4}(\%)$ or lower, and for this strain level the samples are still much closer to an isotropic state. This is demonstrated in Figure 8b, where for all $p_{0}^{\prime}$ and rubber contents considered, the overall $\left(\Phi_{1}-\Phi_{3}\right)$ remained within values of the order of $10^{-3}$, corresponding to a practical isotropic state. For all mixtures, $\left(\Phi_{1}-\Phi_{3}\right)$ for each type of contact sub-network was systematically higher than the overall $\left(\Phi_{1}-\Phi_{3}\right)$. For sand-sand contacts, $\left(\Phi_{1}-\Phi_{3}\right)$ tended to increase as the rubber content increased while $\left(\Phi_{1}-\Phi_{3}\right)$ for rubber-sand contacts showed a more constant response regardless of the rubber content. An opposite trend was found for rubber-rubber particles, i.e. a decay of
$\left(\Phi_{1}-\Phi_{3}\right)$ with an increase in rubber content. At higher contents of rubber, the stress transmission occurred through a more isotropic contact network that primarily comprised rubber particles. At the same time, a less isotropic network comprising sand particles would make it more difficult to transmit stresses through sand-sand contacts, so less stress can be transmitted through the stiff particles which in turn reduces the value of $G_{\max }$.

\subsubsection{Normal contact force anisotropy}

Figure 9a shows the response of $a_{\mathrm{n}}$ against $\varepsilon_{\mathrm{d}}$ for each type of contact and for the clean sand and all mixtures sheared from $p_{0}^{\prime}=100 \mathrm{kPa}$. While $\left(\Phi_{1}-\Phi_{3}\right)$ remained constant, an increase of $a_{\mathrm{n}}$ was noted in particular for sand-sand and rubber-sand contacts. This trend in $a_{\mathrm{n}}$ indicated that contacts were starting to transmit forces in the direction of loading, leading to an increase in the stress difference or deviatoric stress $q=\left(\sigma_{1}^{\prime}-\sigma_{3}^{\prime}\right)$, where $\sigma_{1}^{\prime}$ and $\sigma_{3}^{\prime}$ are the major and minor principal stresses respectively, derived from Equation 1. Thus, any amount of $q$ present in the samples would be the result solely of an increase in $a_{\mathrm{n}}$. For sandsand contacts, $a_{\mathrm{n}}$ is seen to increase only for the clean sand and for the sample M10. Among all samples, rubber-sand contacts presented an increase in $a_{\mathrm{n}}$ with $\varepsilon_{\mathrm{d}}$. On the other hand, rubber-rubber presented almost no change in $a_{\mathrm{n}}$ with an increase of $\varepsilon_{\mathrm{d}}$. In each part of the figure in Figure $9 \mathrm{a}$, the response of $a_{\mathrm{n}}$ for pure sand ( $0 \%$ rubber) is also plotted for comparison. It was revealed that $a_{\mathrm{n}}$ for the sand-sand contacts of pure sand presented the fastest and strongest increase.

In Figure $9 \mathrm{~b}$ a slight increase in the overall $a_{\mathrm{n}}$ as rubber content increased was observed; however, key differences 


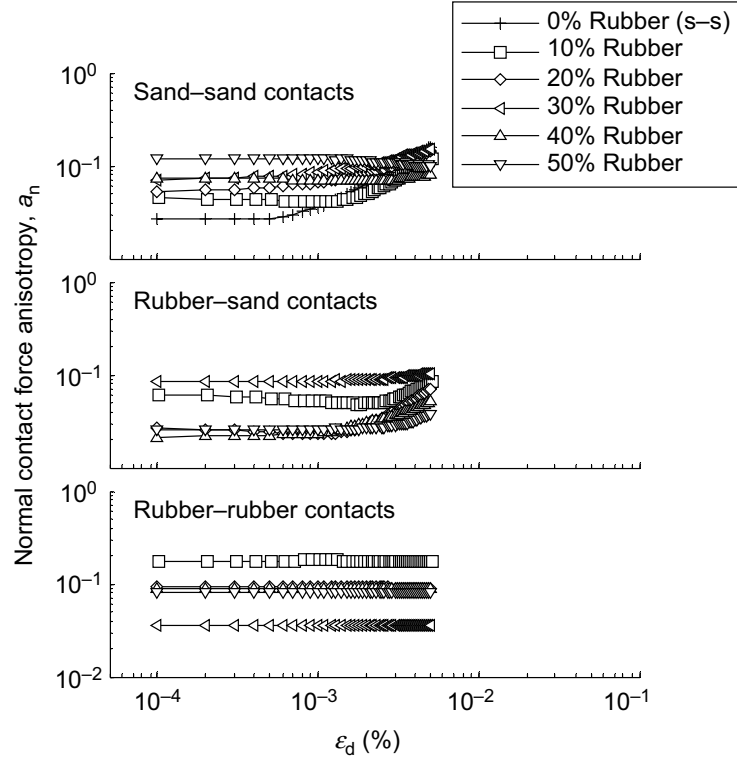

(a)

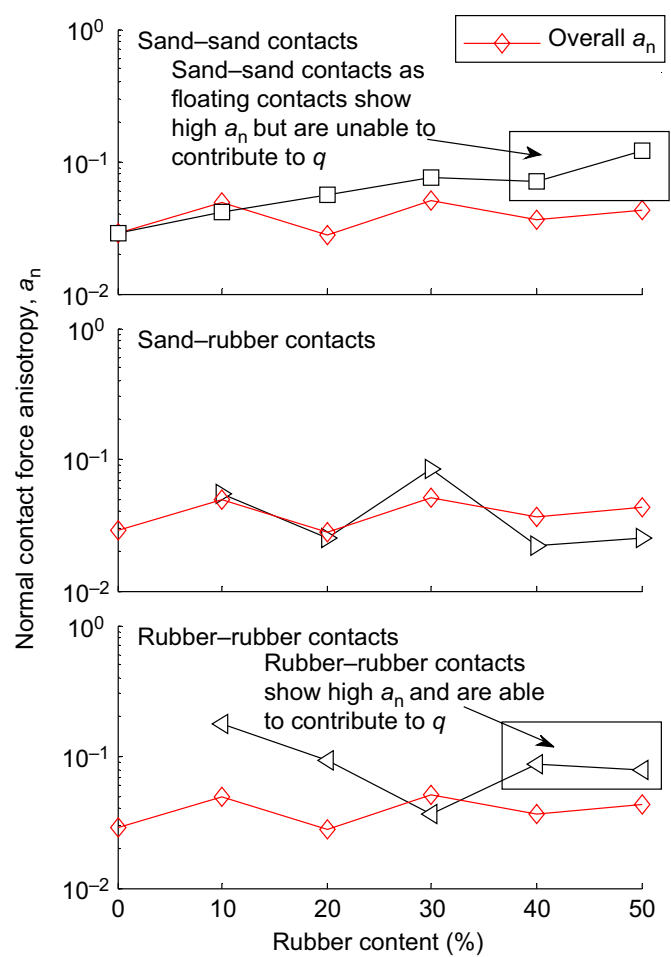

(b)

Figure 9. (a) Normal contact force anisotropy response during small strains for each type of contact and (b) overall contact normal force anisotropy, and by each type of contact against rubber content. $s-s$, sand-sand

can be found when $a_{\mathrm{n}}$ is analysed for each type of contact sub-network. Sand-sand contacts presented an increase in $a_{\mathrm{n}}$ with rubber content. Although a higher $a_{\mathrm{n}}$ would represent higher stresses being transmitted in the direction of loading, this ability should go together with a sufficient amount of contacts to allow stress transmission, which is not the case for sand-sand contacts when the rubber content exceeds $30 \%$ and low values of $Z_{\mathrm{m}}$ dominate. Rubber-sand contacts presented a bi-modal trend, with the rubber content having an interesting peak in $a_{\mathrm{n}}$ at a rubber content of $30 \%$, marking the zone where the stresses are transmitted through the interplay between sand and rubber particles. Beyond a rubber content of $30 \%, a_{\mathrm{n}}$ for rubber-rubber contacts tended to increase with sufficient rubber-rubber contacts, allowing stresses in the direction of loading to be transmitted through rubber-rubber contacts. At low rubber content, stresses in the direction of loading are initially transmitted thorough stiff particles, which allow high stresses at low deformation, resulting in higher $G_{\max }$. On the contrary, at higher rubber contents stresses are transmitted through less stiff particles that require higher deformation to reach a particular deviatoric stress, which is reflected in a decrease in $G_{\text {max }}$.

\subsubsection{Contribution to the overall $\mathrm{a}$}

Following Radjai et al. (1998), Figure 10 shows the cumulative contribution of all contact forces, sand-sand contacts, rubber-sand contacts and rubber-rubber contact forces to the deviatoric stress as a function of the normal contact force normalised by the average normal contact force $\left(f_{\mathrm{n}} /\left\langle f_{\mathrm{n}}\right\rangle\right)$ at $G_{\max }$. Tests of all mixtures sheared from $p_{0}^{\prime}=100 \mathrm{kPa}$ are shown. The overall $q$ at $G_{\max }$ is given by the final point of each curve in the top part of the figure in Figure 10, from where an increase in rubber content showed a marked decrease in $q$. The decay in $q$ with an increase in rubber content may be explained by looking at the force contribution from different contacts. The second part of the figure from the top shows that sand-sand contacts were the main contributors to $q$ when rubber content were less than or equal to $20 \%$. While in the system as a whole contact forces with $f_{\mathrm{n}} /\left\langle f_{\mathrm{n}}\right\rangle=9$ are encountered, sand-sand contacts could transmit forces only up to $f_{\mathrm{n}} /\left\langle f_{\mathrm{n}}\right\rangle \approx 7$. A rubber content of $50 \%$ would lead to a negative contribution to $q$ by the sand-sand contacts. For rubber contents up to $20 \%$, rubber-sand contacts acted as negative contributors to $q$ having an effect on the reduction of the overall deviatoric stress. For rubber contents of $30 \%$ or greater, rubber-sand particles started to contribute positively to $q$; however, from a rubber content of $30 \%$ the majority of contacts were carried by rubber particles, with low stiffness yielding lower stresses. This led to an overall decrease in $q$. The cumulative contribution to $q$ for $50 \%$ rubber content clearly demonstrated a system behaving as a rubber-like material, where the only types of contacts that were contributing positively to $q$ were rubber-sand and rubberrubber contacts.

\subsubsection{Contact force network}

For a thorough illustration of the effect of rubber content on the contact force network, Figure 11 presents, for the 


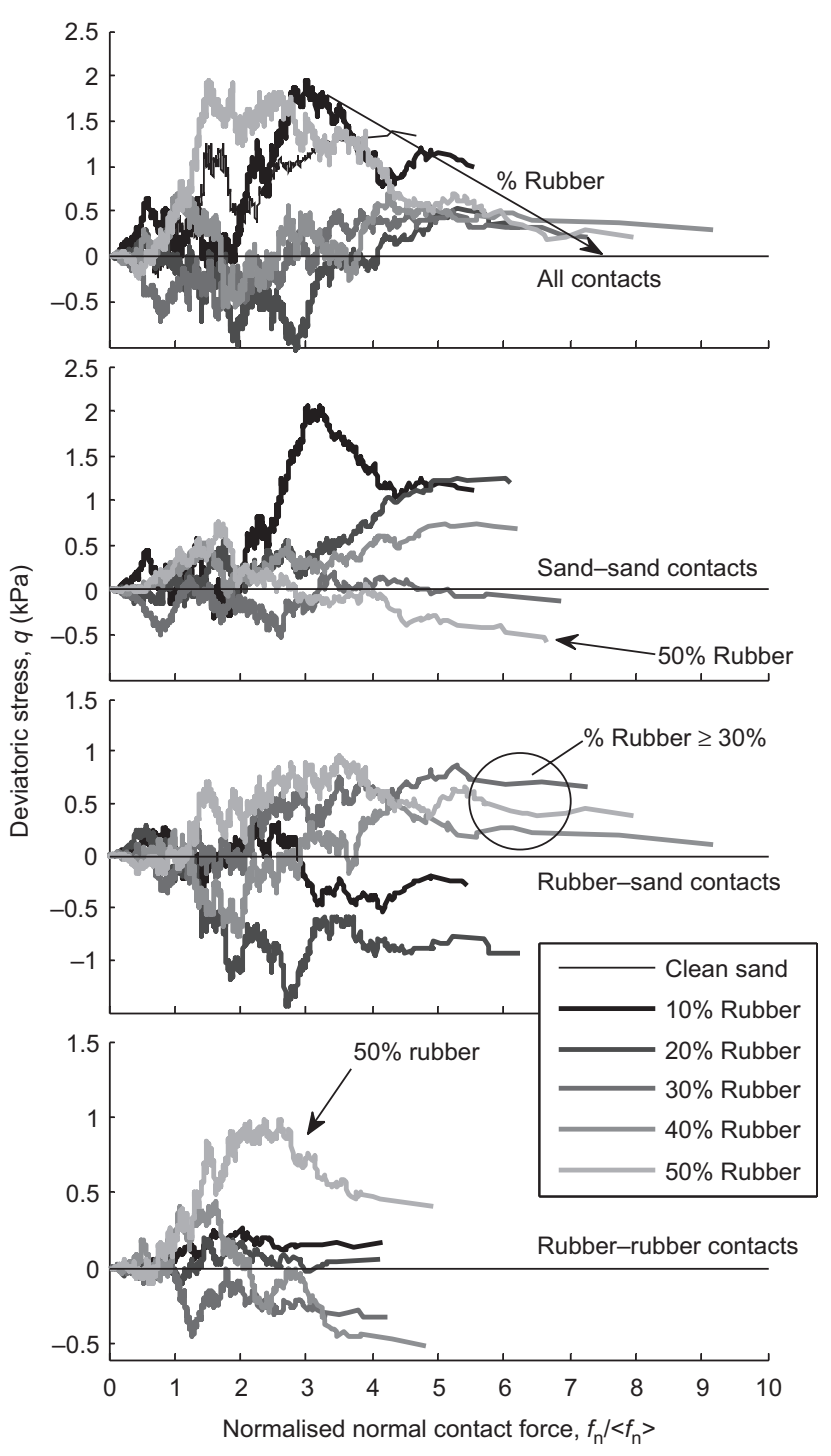

Figure 10. Contact force contribution to deviatoric stress for different rubber contents

clean sand and for all mixtures, the contact force network at $G_{\max }$. The first column of Figure 10 includes all contacts; the second column shows the sand-sand contact sub-network, the third presents the rubber-sand contact sub-network and the fourth the rubber-rubber contact sub-network. Each row in Figure 11 indicates a different percentage of rubber, going from 0 to $50 \%$. The width of the lines is proportional to the contact force magnitude. The sand-sand contacts demonstrated an isotropic and stable contact network for rubber contents up to $20 \%$, but beyond this content a stable contact network could not be distinguished and the sand-sand contacts tended to become a floating contact mode. Thus, the contribution of the sand-sand contacts became negative to the overall $q$ as seen in Figure 10. The strongest contacts by magnitude of normal contact force found in the rubber-sand sub-network, which contributed to the formation of a stable and isotropic contact network, appeared at a rubber content of $30 \%$ and remained fairly similar up to $50 \%$. Rubber-rubber contacts were seen as floating contacts for all percentages of rubber in the mixtures, however, contrary to the trend observed in sandsand contacts, the contribution of the rubber sub-network to the overall deviatoric stress became positive for a rubber content equal to $50 \%$.

\section{CONCLUSIONS}

DEM simulations of triaxial monotonic compression tests on sand-rubber mixtures at a constant volume were discussed with a focus on small strain behaviour. The numerical models with respect to pure sand and pure rubber samples were first calibrated to laboratory test results reported in the literature. A systematic study on the behaviour of sand-rubber mixtures was then conducted using rubber contents that ranged from $10 \%$ to $50 \%$ by mixture weight. Samples were sheared at small strains so the change of elastic shear modulus and the prevailing micro-mechanisms in those mixtures were explored.

The macro-response of the simulated mixtures was seen to agree quantitatively and qualitatively with previous published laboratory test results, showing a decrease in the elastic shear modulus with increasing rubber content. The use of the DEM enabled the collection of micromechanical information that is not easily accessible from laboratory tests. Positions and forces of all particles and contacts were tracked in all tests, with contacts being distinguished by the types of particles that bear the contact. For rubber contents between 0 and $20 \%$, sand-sand contributed the most to the overall stability of the system, and with a clear isotropic network, while rubber-sand and rubber-rubber contacts were seen in a more anisotropic state, in the form of floating contacts unable to produce a stable contact network. A transition zone was detected for rubber contents between 20 and $40 \%$ in which sand-sand and rubber-rubber contacts presented a similar mechanical coordination number, close to 3 . This indicated that the stability of the system was, primarily, due to the interplay of sand-sand and rubber-sand contacts. For rubber contents greater than $40 \%$, sand-sand contacts were seen to contribute less to the overall stability of the system, and a clearly more isotropic sub-network was formed by rubber-sand contacts.

Sand-sand contacts were found to contribute positively to the deviatoric stress in the system, presenting values of $a_{\mathrm{n}}$ similar to the overall for rubber contents of 0 to $20 \%$. In the case of rubber-sand contacts, a maximum in $a_{\mathrm{n}}$ was observed at a rubber content of $30 \%$, indicating the contribution of rubber-sand contacts to the deviatoric stress. A decrease in the contribution to $q$ from rubber-sand contacts was linked to a decrease in $a_{\mathrm{n}}$ for rubber-sand contacts. When the rubber content exceeded $40 \%$, a high $a_{\mathrm{n}}$ was seen for sand-sand and rubber-rubber contacts. However, due to the lack of sufficient contacts from the sand-sand contact network, rubber-rubber contact was the major contributor to the deviatoric stress. 

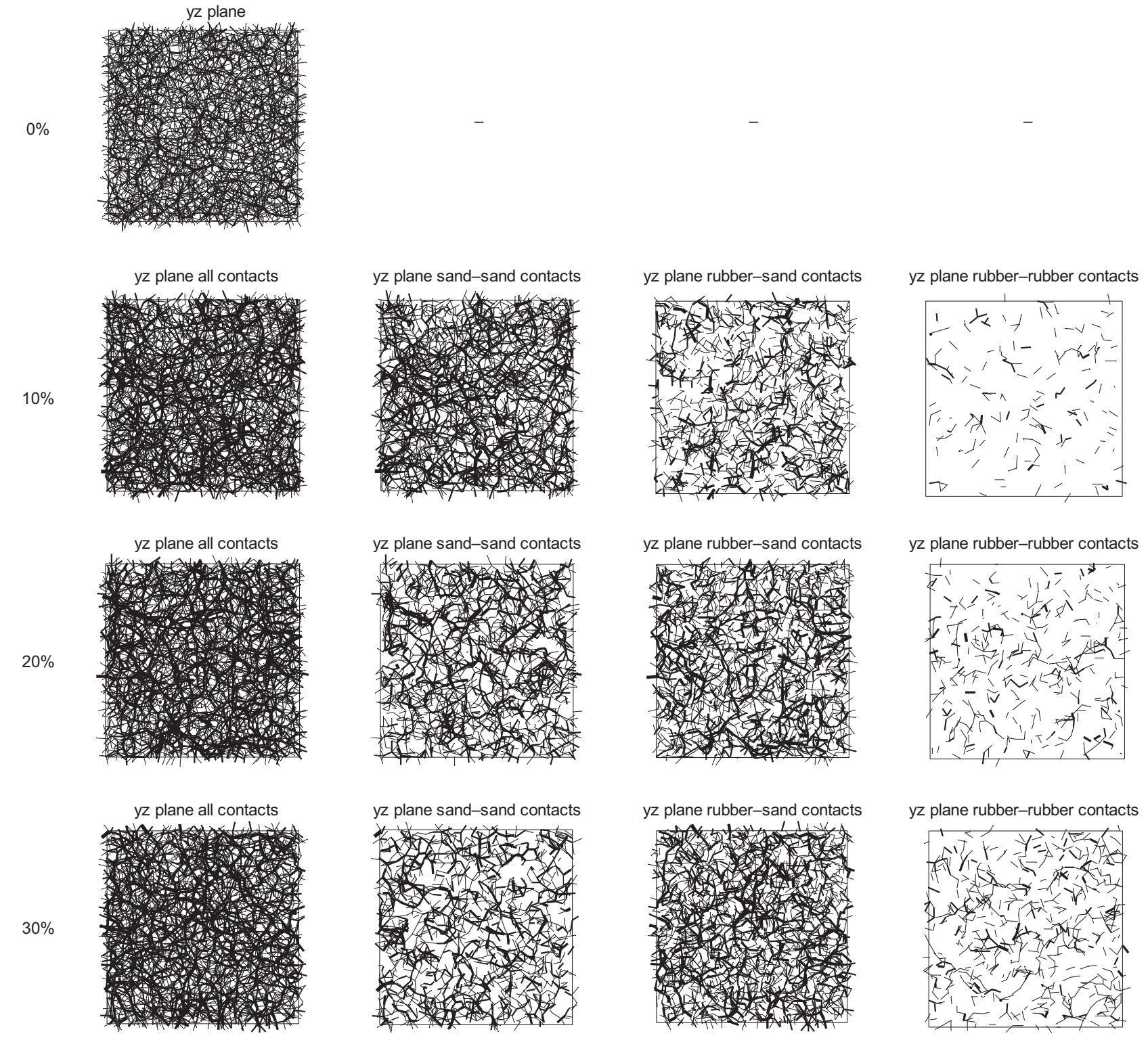

yz plane all contacts
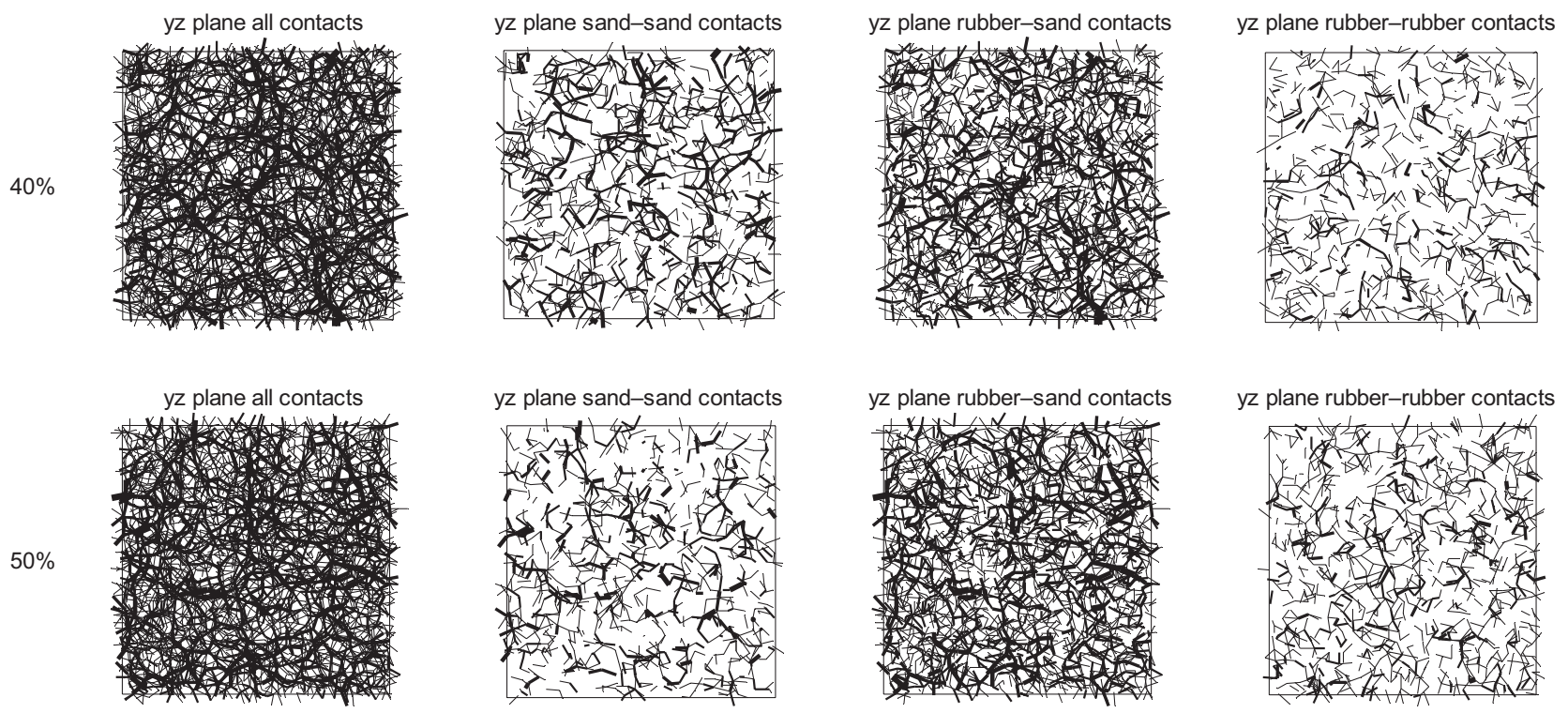

Figure 11. Contact force network at $G_{\max }$ for all mixtures sheared from $p_{0}^{\prime}=100 \mathrm{kPa}$ 


\section{ACKNOWLEDGMENTS}

The authors would like to acknowledge the anonymous reviewers for their constructive comments that helped us to improve the quality of the manuscript. This study was supported by The University of Hong Kong SPACE research fund. This research is conducted using the HKU Information Technology Services research computing facilities that are supported in part by the Hong Kong UGC Special Equipment Grant (SEG HKU09). The third author would like to acknowledge a grant from the Faculty of Engineering UNSW (FRG PS38513) for supporting his trips to Hong Kong for collaboration.

\section{NOTATION}

Basic SI units are given in parentheses.

$a_{\mathrm{n}} \quad$ Normal contact force anisotropy (dimensionless)

$C_{\mathrm{u}} \quad$ coefficient of uniformity

$d$ Particle diameter (m)

$d \varepsilon \quad$ incremental axial deformation

$e_{0}$ Initial void ratio after isotropic compression (dimensionless)

F average normal contact force tensor

$\boldsymbol{f}_{\dot{\mathrm{e}}}^{\mathbf{e}}$ inter-particle contact force

$f_{\mathrm{n}} \quad$ Normal contact force (N)

$G \quad$ Elastic secant shear modulus $(\mathrm{Pa})$

$G_{\max } \quad$ Maximum elastic secant shear modulus (Pa)

$G^{\mathrm{p}} \quad$ Particle shear modulus (Pa)

I Inertial number (dimensionless)

$I_{i}^{\mathrm{e}}$ branch vector $(\mathrm{m})$

$k_{\mathrm{n}}, k_{\mathrm{t}} \quad$ Normal and tangential contact stiffness respectively $(\mathrm{N} / \mathrm{m})$

$N_{\mathrm{c}} \quad$ Number of contacts in the system (dimensionless)

$p^{\prime} \quad$ Mean effective stress $(\mathrm{kPa})$

$p_{0}^{\prime} \quad$ Mean effective stress after isotropic compression $(\mathrm{Pa})$

$q \quad$ Deviatoric stress $q=\sigma_{1}^{\prime}-\sigma_{3}^{\prime}(\mathrm{Pa})$

$\tilde{R}$ equivalent radius between two particles in contact

$t_{\text {crit }} \quad$ Critical time step (s)

$V$ volume of the periodic cell $\left(\mathrm{m}^{3}\right)$

$Z_{\mathrm{m}} \quad$ Mechanical coordination number (dimensionless)

$\varepsilon_{\mathrm{d}} \quad$ Shear strain (dimensionless)

$\varepsilon_{\mathrm{q}} \quad$ Shear strain $\varepsilon_{\mathrm{q}}=2 / 3\left(\varepsilon_{1}-\varepsilon_{3}\right)$ (dimensionless)

$\dot{\varepsilon} \quad$ Strain rate $\left(\mathrm{s}^{-1}\right)$

$\varepsilon_{1} ; \varepsilon_{2} ; \varepsilon_{3} \quad$ Major, intermediate and minor principal strains $\left(\varepsilon_{2}=\varepsilon_{3}\right)$ (dimensionless)

$\mu$ Inter-particle friction coefficient (dimensionless)

$\mu_{\text {iso }} \quad$ inter-particle friction coefficients assigned during isotropic compression

$v$ Particle Poisson's ratio (dimensionless)

$\rho \quad$ Particle density $\left(\mathrm{kg} / \mathrm{m}^{3}\right)$ $\sigma_{1}^{\prime} ; \sigma_{2}^{\prime} ; \sigma_{3}^{\prime} \quad$ Major, intermediate and minor principal stresses $\left(\sigma_{2}^{\prime}=\sigma_{3}^{\prime}\right)(\mathrm{Pa})$

$\overline{\boldsymbol{\sigma}}_{i j} \quad$ stress tensor

$\left(\Phi_{1}-\Phi_{3}\right) \quad$ Deviatoric fabric (dimensionless)

\section{REFERENCES}

Anastasiadis, A., Senetakis, K. \& Pitilakis, K. (2012). Small-strain shear modulus and damping ratio of sand-rubber and gravelrubber mixtures. Geotechnical and Geological Engineering, 30, No. 2, 363-382.

ASTM D6270-98 Standard test methods for use of scrap tires in civil engineering applications, Annual Book of ASTM Standards. ASTM International, West Conshohocken, PA, USA.

ASTM D2487-00 Standard practice for classification of soils for engineering purposes (Unified Soil Classification System), Annual Book of ASTM Standards. ASTM International, West Conshohocken, PA, USA.

Bachrach, R., Dvorkin, J. \& Nur, A. M. (2000). Seismic velocities and Poisson's ratio of shallow unconsolidated sands. Geophysics, 65, No. 2, 559-564

Bagi, K. (1996). Stress and strain in granular assemblies. Mechanics of Materials, 22, No. 3, 165-177.

Barreto, D. \& O'Sullivan, C. (2012). The influence of interparticle friction and the intermediate stress ratio on soil response under generalised stress conditions. Granular Matter, 14, No. 4, 505-521.

Beatty, J. R. (1991). Physical properties of rubber compounds. Mechanics of Pneumatic Tires, Clark, S. K., Editor, National Highway Traffic Administration, U. S. Department of Transportation, Washington, DC, USA, pp. 871-885.

Bernal, A., Salgado, R., Swan, R. H. Jr \& Lovell, C. W. (1997) Interaction between tire shreds, rubber-sand and geosynthetics. Geosynthetics International, 4, No. 6, 623-643.

Bosscher, P. J., Edil, T. B. \& Kuraoka, S. (1997). Design of highway embankments using tire chips. Journal of Geotechnical and Geoenvironmental Engineering ASCE, 123, No. 4, 295-304.

Christ, M., Park, J. \& Hong, S. (2010). Laboratory Observation of the response of a buried pipeline to freezing rubber-sand backfill. Journal of Materials in Civil Engineering ASCE, 22, No. 9, 943e950.

Cundall, P. A. \& Strack, O. D. L. (1979). A discrete element model for granular assemblies. Geotechnique, 29, No. 1, 47-65.

daCruz, F., Emam, S., Prochnow, M., Roux, J. N. \& Chevoir, F. (2005). Rheophysics of dense granular materials: discrete simulation of plane shear flows. Physical Review E, 72, 021309.

Edeskar, T. (2006). Use of Tyre Shreds in Civil Engineering Applications-Technical and Environmental Properties, PhD dissertation, Lulea University of Technology, Department of Civil and Environmental Engineering, Division of Mining and Geotechnical Engineering, Luleå, Sweden.

Edil, T. B. (2004). A review of mechanical and chemical properties of shredded tires and soil mixtures. In Recycled Materials in Geotechnics, Aydilek, A. H. and Wartman, J., Editors, Geo-technical Special Publication No. 127, Baltimore, MD, USA, ASCE, Reston, VA, USA, pp. 1-21.

Edincliler, A. (2007). Using waste tire-soil mixtures for embankment construction. In Proceedings of the International Workshop on Scrap Tire Derived Geomaterials-Opportunities and Challenges, Hazarika, H. and Yasuhara, K., Editors, Yokosuka, Japan, pp. 319-328.

Edincliler, A. \& Ayhan, V. (2010). Influence of tyre fiber inclusions on shear strength of sand. Geosynthetics International, 17, No. 4, 183-192.

Edincliler, A. \& Cagatay, A. (2013). Weak subgrade improvement with rubber fibre inclusions. Geosynthetics International, 20, No. 1, $39-46$. 
Evans, T. M. \& Valdes, J. R. (2011). The microstructure of particulate mixtures in one-dimensional compression: numerical studies. Granular Matter, 13, No. 5, 657-669.

Guo, N. \& Zhao, J. (2013). The signature of shear-induced anisotropy in granular media. Computers and Geotechnics, 47, 1-15.

Hazarika, H., Kohama, E. \& Sugano, T. (2008). Underwater shake table tests on waterfront structures protected with tire chips cushion. Journal of Geotechnical and Geoenvironmental Engineering ASCE, 134, No. 12, 1706-1719.

Hecke, M. V. (2010). Jamming of soft particles: geometry, mechanics, scaling and isostaticity. Journal of Physics: Condense Matter, 22, No. 3, 033101.

Huang, X., Hanley, K. J., O’Sullivan, C. \& Kwok, C. Y. (2014). Effect of sample size on the response of DEM samples with a realistic grading. Particuology, 15, 107-115.

Humphrey, D. N. \& Sandford, T. C. (1993). Tire chips as lightweight subgrade fill and retaining wall backfill. In Proceedings of the Symposium on Recovery and Effective Reuse of Discarded Materials and By-Products for Construction of Highway Facilities, U.S. Department of Transportation, Federal Highway Administration, pp. 5-87.

Humphrey, D., Cosgrove, T., Whetten, N. L. \& Herbert, R. (1997). Tire chips reduce lateral earth pressure against the walls of a rigid frame bridge. Seminar on Rehabilitation and Upgrades in Civil and Environmental Engineering, Orono, Maine, ASCE, Reston, VA, USA.

Kaneda, K., Hazarika, H. \& Yamazaki, H. (2007). The numerical simulation of earth pressure reduction using tire chips in backfill. In Proceedings of the International Workshop on Scrap Tire Derived Geomaterials-Opportunities and Challenges, Hazarika, H. and Yasuhara, K., Editors, Yokosuka, Japan, pp. 245-251.

Kim, H. K. \& Santamarina, J. C. (2008). Sand-rubber mixtures (large rubber chips). Canadian Geotechnical Journal, 45, No. 10, 1457-1466.

Lee, J. H., Salgado, R., Bernal, A. \& Lovell, C. W. (1999). Shredded tires and rubber-sand as lightweight backfill. Journal of Geotechnical and Geoenvironmental Engineering ASCE, 125, No. 2, 132-141.

Lee, J. S., Dodds, J. \& Santamarina, J. C. (2007). Behavior of rigid-soft particle mixtures. Journal of Materials in Civil Engineering, 19, No. 2, 179-184.

Lee, C. Shin, H. \& Lee, J. (2014). Behaviour of sand-rubber particle mixture: experimental observations and numerical simulations. International Journal for Numerical and Analytical Methods in Geomechanics, 38, No. 16, 1651-1663.

Li, L., Xiao, H., Ferreira, P. \& Cui, X. (2016). Study of a small scale tyre-reinforcement embankment. Geotextiles and Geomembranes, 44, No. 2, 201-208.

Manificat, G. \& Guéguen, Y. (1998). What does control $V_{\mathrm{p}} / V_{\mathrm{s}}$ in granular rocks? Geophysical Research Letters, 35, No. 3, 381-384.

Mashiri, M. S., Vinod, J. S., Sheikh, M. N. \& Tsang, H. (2015). Shear strength and dilatancy behaviour of sand-tyre chip mixtures. Soils and Foundations, 55, No. 3, 517-528.

Mavronicola, E., Komodromos, P. \& Charmpis, D. (2010). Numerical investigation of potential usage of rubber-soil mixtures as a distributed seismic isolation approach. Proceedings of the Tenth International Conference on Computational Structures Technology, Adam, J. M., Pallare, F. J., Bru, R. and Romero, M. L., Editors, Civil-Comp Press, Stirlingshire, UK, Paper 168.

MiDi, G. D. R. (2004). On dense granular flows. European Physical Journal E, 14, No. 4, 341-365.

Mindlin, R. D. \& Deresiewicz, H. (1953). Elastic spheres in contact under varying oblique forces. Journal of Applied Mechnanics, 20, 327-344.

Minh, N. H. \& Cheng, Y. P. (2013). A DEM investigation of the effect of particle-size distribution on one-dimensional compression. Géotechnique, 63, No. 1, 44-53.

Moghaddas Tafreshi, S. N., Khalaj, O. \& Dawson, A. R. (2014). Repeated loading of soil containing granulated rubber and multiple geocell layers. Geotextiles and Geomembranes, 42, No. 1, 25-38.
Narejo, D. B. \& Shettima, M. (1995). Use of recycled automobile tires to design landfill components. Geosynthetics International, 2, No. 3, 619-625.

O’Donovan, J., O’Sullivan, C. \& Marketos, G. (2013). Two-dimensional discrete element modelling of bender element tests on an idealised granular material. Granular Matter, 14, No. 6, 733-747.

O'Sullivan, C. (2011). Particulate Discrete Element Modelling, Spon Press, London, UK.

O'Sullivan, C. \& Bray, J. (2004). Selecting a suitable time step for discrete element simulations that use the central difference time integration scheme. Engineering Computations, 21, No. 2/3/4, 278-303.

Özkul, Z. H. \& Baykal, G. (2007). Shear behaviour of compacted rubber fiber-clay composite in drained and undrained loading. Journal of Geotechnical and Geoenvironmental Engineering ASCE, 133, No. 7, 767-781.

Oztoprak, S. \& Bolton, M. D. (2013). Stiffness of sands through a laboratory database. Geotechnique, 63, No. 1, 54-70.

Pitilakis, K., Anastasiadis, A., Pitilakis, D., Trevlopoulos, K. \& Senetakis, K. (2010). Advances in performance-based earthquake engineering, chapter 6: elastic demand spectra. Geotechnical, Geological, and Earthquake Engineering, Fardis, M., Editor, vol. 13, Part I, Springer Science \& Business Media, Berlin, Germany, pp. 89-99.

Pitilakis, K., Trevlopoulos, K., Anastasiadis, A. \& Senetakis, K. (2011). Seismic response of structures on improved soil. In Proceedings of the 8th International Conference on Structural Dynamics (EURODYN2011), European Association for Structural Dynamics, Leuven, Belgium.

Plimpton, S. (1995). Fast parallel algorithms for short-range molecular dynamics. Journal of Computational Physics, 117, No. 1, 1-19.

Potyondy, D. O. \& Cundall, P. A. (2004). A bonded-particle model for rock. International Journal of Rock Mechanics and Mining Sciences, 41, No. 8, 1329-1364.

Radjai, F., Wolf, D. E., Jean, M. \& Moreau, J. (1998). Bimodal character of stress transmission in granular packings. Physical Review Letters, 80, No. 1, 61-64.

Reddy, K. R. \& Saichek, R. E. (1998). Characterization and performance assessment of shredded scrap tires as leachate drainage material in landfills. In Proceedings of the 14th International Conference on Solid Waste Technology and Management, Philadelphia, USA, The Journal of Solid Waste Technology and Management, Chester, PA, USA.

Rothenburg, L. \& Bathurst, R. J. (1989). Analytical study of induced anisotropy in idealized granular materials. Géotechnique, 39, No. 4, 601-614.

Satake, M. (1982). Fabric tensor in granular materials. In IUTAM Symposium on Deformations and Failure of Granular Materials, Vermeer, P. A. and Luger, H. J., Editors, Balkema, Rotterdam, The Netherlands, pp. 63-68.

Senetakis, K. \& Anastasiadis, A. (2015). Effects of state of test sample, specimen geometry and sample preparation on dynamic properties of rubber-sand mixtures. Geosynthetics International, 22, No. 4, 301-310.

Senetakis, K., Anastasiadis, A., Trevlopoulos, K. \& Pitilakis, K. (2009). Dynamic Response of SDOF systems on soil replaced with sand/rubber mixture. In Proceedings of the ECOMAS Thematic Conference on Computation Methods in Structural Dynamics and Earthquake Engineering, Rhodes, Greece.

Senetakis, K., Anastasiadis, A. \& Pitilakis, K. (2012a). Dynamic properties of sand/rubber (SRM) and gravel/rubber (GRM) mixtures in a wide range of shearing strain amplitudes. Soil Dynamics and Earthquake Engineering, 33, No. 1, 38-53.

Senetakis, K., Anastasiadis, A. \& Pitilakis, K. (2012b). The small-strain shear modulus and damping ratio of quartz and volcanic sands. Geotechnical Testing Journal, 35, No. 6, pp. 1-17.

Senetakis, K., Coop, M. R. \& Todisco, M. C. (2013a). Tangential load-deflection behaviour at the contacts of soil particles. Géotechnique Letters, 3, No. 2, 59-66.

Senetakis, K., Coop, M. R. \& Todisco, M. C. (2013b). The inter-particle coefficient of friction at the contacts of Leighton 
Buzzard sand quartz minerals. Soils and Foundations, 53, No. 5, 746-755.

Simmons, G. \& Brace, W. F. (1965). Comparison of static and dynamic measurements of compressibility of rocks. Journal of Geophysical Research, 70, No. 22, 5649-5656.

Simpson, B., O'Riordan, H. J. \& Croft, D. D. (1979). A computer model for the analysis of ground movements in London Clay. Géotechnique, 29, No. 2, 149-175.

Sitharam, T., Vinod, J. \& Ravishankar, B. (2009). Post-liquefaction undrained monotonic behaviour of sands: experiments and DEM simulations. Géotechnique, 59, No. 9, 739-749.

Tanchaisawat, T., Bergado, D. T., Voottipruex, P. \& Shehzad, K. (2010). Interaction between geogrid reinforcement and tire chip-sand lightweight backfill. Geotextiles and Geomembranes, 28, No. 1, 119-127.

Tavaloki Mehrjardi, G. H., Moghaddas Tafreshi, S. N. \& Dawson, A. R. (2012). Combined use of geocell reinforcement and rubber-soil mixtures to improve performance of buried pipes. Geotextiles and Geomembranes, 34, 116-130.

Thornton, C. (2000). Numerical simulations of deviatoric shear deformation of granular media. Géotechnique, 50, No. 1, 43-53.
Tsang, H. H. (2008). Seismic isolation by rubber-soil mixtures for developing countries. Earthquake Engineering and Structural Dynamics, 37, No. 2, 283-303.

Uchumura, T., Chi, N., Nirmalan, S., Sato, T., Meidani, M. \& Towhata, I. (2007). Shaking table tests on effect of tire chips and sand mixture in increasing liquefaction resistance and mitigating uplift of pipe. In Proceedings, International Workshop on Scrap Tire Derived Geomaterials-Opportunities and Challenges, Hazarika, H. and Yasuhara, K., Editors, Yokosuka, Japan, pp. 179-186.

Valdes, J. R. \& Evans, M. T. (2008). Sand-rubber mixtures: experiments and numerical simulations. Canadian Geotechnical Journal, 45, No. 4, 588-595.

Wei, L. M. \& Yang, J. (2014). On the role of grain shape in static liquefaction of sand-fines mixtures. Géotechnique, 64, No. 9, 740-745.

Yimsiri, S. \& Soga, K. (2010). DEM analysis of soil fabric effects on behaviour of sand. Géotechnique, $\mathbf{6 0}$, No. 6, 483-495.

Zornberg, J. G., Carbal, A. R. \& Viratjandr, C. (2004). Behaviour of tire shred-sand mixtures. Canadian Geotechnical Journal, 41, No. 2, 227-241.

The Editor welcomes discussion on all papers published in Geosynthetics International. Please email your contribution to discussion@geosynthetics-international.com 